\title{
Adding a Structural Context to the Deprotometalation and Trans- Metal-Trapping Chemistry of Phenyl-substituted Benzotriazole
}

\author{
M. Ángeles Fuentes, ${ }^{[a]}$ Alan R. Kennedy, ${ }^{[a]}$ Robert E. Mulvey, ${ }^{*[a]}$ John A. Parkinson, ${ }^{[a]}$ Toni Rantanen, ${ }^{[b]}$ \\ Stuart D. Robertson, ${ }^{[\mathrm{a}]}$ and Victor Snieckus ${ }^{[\mathrm{c}]}$
}

\begin{abstract}
Organometallic bases are becoming increasingly complex since mixing components can lead to bases superior to single component bases. To better understand this superiority, it is useful to study metalated intermediate structures prior to quenching. This study is on 1-phenyl-1H-benzotriazole, which was previously deprotonated by an in situ $\mathrm{ZnCl}_{2} \cdot$ TMEDA/LiTMP mixture and then iodinated. Here, reaction with LiTMP exposes the deficiency of the single component base as the crystalline product obtained was [ $[\{4-$ $\mathrm{R}$-1-(2-lithiophenyl)-1H-benzotriazole-3THF $\}_{2}$ ], $\left[\mathrm{R}=2-\mathrm{C}_{6} \mathrm{H}_{4}(\mathrm{Ph}) \mathrm{NLi}\right.$, in which ring opening of benzotriazole and $\mathrm{N}_{2}$ extrusion had occurred. Supporting lithiation by adding $\mathrm{Bu}_{2} \mathrm{Al}(\mathrm{TMP})$ induces trans-metaltrapping where $\mathrm{C}$-Li bonds transform into $\mathrm{C}$-Al bonds to stabilise the metalated intermediate. X-ray diffraction studies revealed homodimeric $\left[\left(4-\mathrm{R}^{\prime}-1 \text {-phenyl-1H-benzotriazole }\right)_{2}\right], \quad\left[\mathrm{R}^{\prime}=(\mathrm{iBu})_{2} \mathrm{Al}(\mu-\right.$ TMP $)$ Li], and its heterodimeric isomer $\left[\left(4-\mathrm{R}^{\prime}-1-\right.\right.$ phenyl-1Hbenzotriazole $)\left\{1-\left(2-R^{\prime}\right.\right.$-phenyl)-1H-benzotriazole $\}$, whose structure and slow conformational dynamics (activation enthalpy $\square H^{\ddagger}=71 \pm 5$ $\mathrm{kJ} \mathrm{mol}^{-1}$, Gibbs free activation energy at $298 \mathrm{~K}, \square G^{\ddagger} 298=67 \pm 5 \mathrm{~kJ}$ $\mathrm{mol}^{-1}$ and activation energy $E_{\mathrm{a}}=75.4 \pm 0.4 \mathrm{~kJ} \mathrm{~mol}^{-1}$ ) were probed by solution NMR spectroscopy.
\end{abstract}

\section{Introduction}

The benefit of studying the structures of organometallic bases (deprotometalating agents) and the metalated intermediates of their deprotonation ( $\mathrm{C}-\mathrm{H}$ to $\mathrm{C}$-metal exchange) reactions is all too apparent. Conveying this idea in a complete context, Schlosser ${ }^{[1]}$ remarked eloquently that "no difference in organometallic reactivity patterns can be rationalised unless the metal and its specific interactions with the accompanying carbon backbone, the surrounding solvent, and the substrate of the reaction, are explicitly taken into account". In other words, reactivity and structures are inseparable. At the time this

[a] Dr. M. Á. Fuentes, Dr. A. R. Kennedy, Prof. R. E. Mulvey, Dr. J. A. Parkinson, Dr. S. D. Robertson

WestCHEM, Department of Pure and Applied Chemistry

University of Strathclyde, Glasgow, G1 1XL (UK)

Fax: (+44)141-548-4787

E-mail: r.e.mulvey@strath.ac.uk

[b] Dr. T. Rantanen

Snieckus Innovations, Innovation Park,

945 Princess Street, Kingston, Ontario, K7L 3N6 (Canada)

[c] Prof. V. Snieckus

Department of Chemistry

Queen's University, 90 Bader Lane, Kingston, Ontario, K7L 3N6

(Canada)

Supporting information for this article is given via a link at the end of the document. quotation was written, most organometallic bases were singlemetal species; whereas today mixed-metal bases are often used in synthetic campaigns. This presence of two or occasionally more distinct metals within the base composition can add greatly to the complexity involved, making structural information even more valuable towards attaining a full understanding of the chemistry. Without such structural characterisation, our recent report ${ }^{[2]}$ of rare ortho-meta' and meta-meta' dideprotonations of several aromatic substrates, the latter, a seeming heterodoxy to the doctrine of directed ortho-metalation (DoM), ${ }^{[3]}$ may have lacked a plausible explanation. However, the rationale proposed was of a special template effect whereby the ring structure of the "pre-inverse-crown" base ${ }^{[4]}$ controls the number and regioselectivity of deprotonations within the "inverse crown" product to a greater extent than the directing group attached to the aromatic substrate. This small but significant step towards realising designer bases has stimulated us to explore areas of deprotometalation chemistry where structural information is scant or missing completely. Mongin's recent report ${ }^{[5]}$ of the deprotonation of 1-aryl- $H$-benzotriazoles by a lithium-zinc mixture (Scheme 1 shows examples where aryl = phenyl) caught our eye in this context for its interesting regioselectivities determined indirectly through iodination of the active metallo intermediates. This paper also summarised the few lithiation studies carried out on these heterocycles, none of which, significantly, reported any structurally characterised lithio intermediates. Surprisingly few crystal structures are known even for $\mathrm{N}$-lithiated benzotriazoles. A notable exception is cationic $\left[\left\{(\mathrm{PMDETA} \cdot \mathrm{Li})_{2}\left(\mathrm{C}_{6} \mathrm{H}_{4} \mathrm{~N}_{3}\right)\right\}^{+}\right]$reported by Wright, ${ }^{[6]}$ which was not synthesised from benzotriazole $\left(\mathrm{C}_{6} \mathrm{H}_{4} \mathrm{~N}_{3} \mathrm{H}\right.$, btaH) but via a remarkable oxidative dehydrocoupling of o-phenylenediamine triggered by a lithium-tin(II) alkyl-amido base. While seminal studies by Katritzky[] have established benzotriazole as a versatile synthetic auxiliary, its importance extends to numerous material and biochemical applications. Here in this study we set about gaining reactivity and structural insights into the deprotometalation chemistry of 1-phenyl-1H-benzotriazole 1.

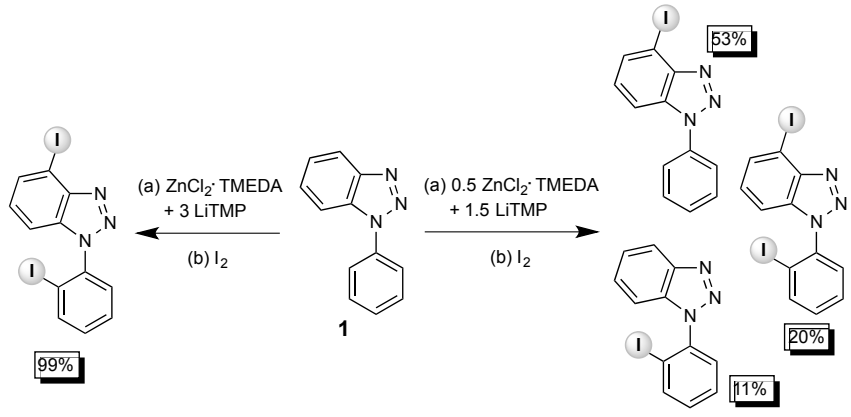

Scheme 1. Stepwise deprotozincation/iodination reactions of 1-phenyl-1Hbenzotriazole as reported by Mongin et al. ${ }^{[5]}$ 


\section{Results and Discussion}

Deprotolithiation without trans-metal-trapping: With only modest success in trying to fill the structural gaps in knowledge between reactants and iodinated products in the mixed lithiumzinc base system (see later in article), we turned to a related lithium-aluminium system that has previously provided valuable insights into related deprotometalations of anisole ${ }^{[8]}$ and $\mathrm{N}, \mathrm{N}$ dimethylphenylethylamine (DMPEA). ${ }^{[9]}$ An added incentive for including aluminium is the paucity of crystallographically characterised aluminium benzotriazoles with a rare exception being a series of phenoxybenzotriazole derivatives studied for their photoluminescent properties. ${ }^{[10]}$

In the lithium-aluminium system in question, LiTMP performs the metalation of the $\mathrm{C}-\mathrm{H}$ substrate while the dialkylaluminium amide $i \mathrm{Bu}_{2} \mathrm{Al}(\mathrm{TMP})$ performs the trans-metal-trapping of the developing $\mathrm{C}^{-}$carbanion (TMP $=2,2,6,6$-tetramethylpiperidide). As explained elsewhere ${ }^{[8]}$ we do not use the more common term transmetalation as it usually signifies the exchange of metals in separate compounds, whereas here the aluminium compound inserts into the C-Li bond to trap and simultaneously stabilise the carbanion within the one mixed lithium-aluminium compound, hence trans-metal-trapping seems more appropriate. We first tested the lithiation of $\mathbf{1}$ with LiTMP on its own. Though lithiations of benzotriazoles have normally been performed at low temperatures, for a direct comparison with the aluminium system we carried out the reaction at room temperature for two hours in $n$-hexane and then THF was added to the mixture. As expected this unsupported (without aluminium trapping) lithiation reaction was unclean producing an unpromising dark solution the NMR spectrum of which, in showing a plethora of overlapping resonances, proved to be of little diagnostic value (see Supporting Information). That notwithstanding, freezer cooling of this dark mixture to $-15^{\circ} \mathrm{C}$ over several days produced a small crop of red crystals identified by $X$-ray crystallography as the dilithio benzotriazole derivative $[\{4-\mathrm{R}-1-(2$-lithiophenyl)- $1 \mathrm{H}$ benzotriazole.3THF $\}_{2}$, 2, where $\mathrm{R}=2-\mathrm{C}_{6} \mathrm{H}_{4}(\mathrm{Ph}) \mathrm{NLi}$. The crystalline yield obtained was only $10 \%$.

As revealed in Figure 1a, crystalline 2 exists as a discrete, centrosymmetric dimer. The structure is easily comprehensible from consideration of a monomeric unit. A phenyl-benzotriazole scaffold is substituted in two distinct positions. The 4-position of the benzo ring is occupied by a diphenylamidolithium fragment (containing Li1-N4) connected by a new C-C (C2-C19) bond involving ortho-C(19), (see Figure 2a) while the 2-position of the 1-phenyl substituent has been lithiated (Li2-C8, see Figure $2 b$ ). Dimerisation occurs through four bonds, Li1-N2' (the central N atom of the triazole unit), Li2-N4' (the $\mathrm{N}$ atom of the amide) and their symmetrical equivalents Li1'-N2 and Li2'-N4 respectively. Bonding to two triazole $\mathrm{N}$ atoms (N3 and $\mathrm{N}^{\prime}$ ), one amido $\mathrm{N}$ atom (N4) and one THF O atom (O1), distorted tetrahedral Li1 is distinct from Li2 whose distorted tetrahedral environment is made up of an ortho- $\mathrm{C}$ atom (C8), an amido $\mathrm{N}$ atom (N4) and two THF $\mathrm{O}$ atoms (O2 and $\mathrm{O} 3$ ). A different perspective of the structure (Figure $1 \mathrm{~b}$ ) shows the internal Li1/Li1' atoms belong to an essentially planar 6-5-6-5-6 fused ring system (plane of central 6 membered ring lies at $13.64(5)^{\circ}$ to benzotriazole plane)

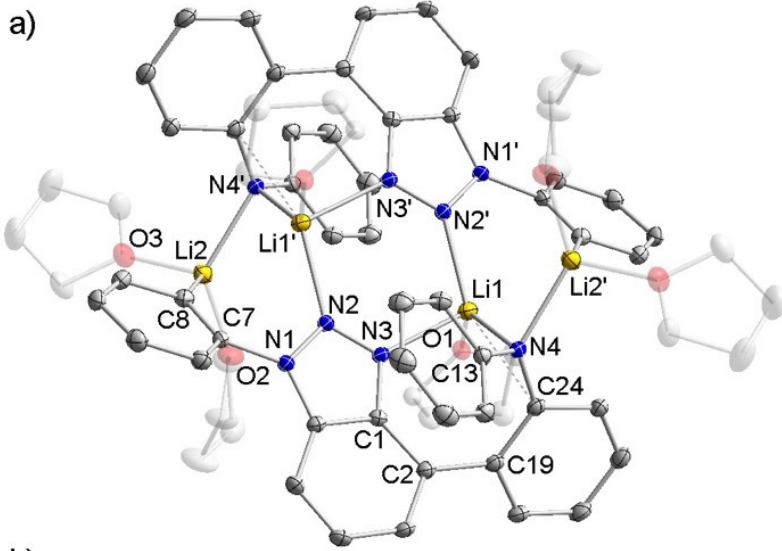

b)

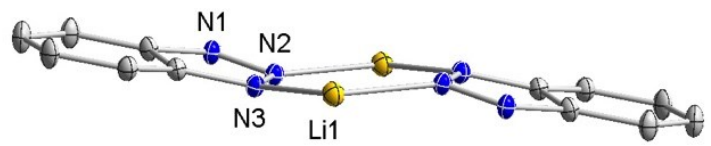

Figure 1. (a) Molecular structure of [\{4-R-1-(2-lithiophenyl)-1Hbenzotriazole-3THF $\left.\}_{2}\right], \quad\left[\mathrm{R}=2-\mathrm{C}_{6} \mathrm{H}_{4}(\mathrm{Ph}) \mathrm{NLi}\right], \quad 2$. Thermal ellipsoids are displayed at $35 \%$ probability, hydrogen atoms and one disordered tetrahydrofuran molecule of crystallization have been omitted for clarity. The dashed lines illustrate the $\mathrm{Li} \cdots \mathrm{C}$ contact. Symmetry operation to generate equivalent atoms denoted ': $-\mathrm{x}, 1-\mathrm{y}, 1-\mathrm{z}$. Selected bond lengths $(\AA)$ and bond angles ('): Li1-N2', 2.087(5); Li1-N3, 2.102(5); Li1-N4, 2.140(5); Li1-O1, 1.994(4); Li2-N4', 2.093(5); Li2-C8, 2.178(5); Li1 ‥C24, 2.588(5); Li2-O2, 2.025(5); Li2-O3, 1.990(5); C2-C19, 1.481(3); N1-N2, 1.345(3); N2-N3, 1.309(3); N4-C24, 1.390(3); N4-C13, 1.385(3); N2'-Li1-N3, 103.13(19); N2'Li1-O1, 108.8; N2'-Li1-N4, 120.8(2); N3-Li1-O1, 95.62(19); N4-Li1-O1, 128.3(2); N3-Li1-N4, 86.93(17); Li1-N4-Li2', 81.44(18); Li1-N4-C13, 118.84(19); Li1-N2'-N1', 117.97(18); Li1-N3-N2, 125.53(19); Li1-N4-C24 91.83(18); N4'-Li2-C8, 110.4(2); N4'-Li2-O2, 121.9(2); N4'-Li2-O3, 102.8(2); O2-Li2-O3, 97.9(2); O2-Li2-C8, 108.9(2); O3-Li2-C8, 114.3(2); Li2-C8-C7, 130.1(2); N1-N2-N3, 109.38(18); C1-C2-C19, 124.6(2); N4-C24-C19, 125.8(2); C24-C19-C2, 122.7(2). (b) Cut out of the core of 2 highlighting its $6-5-6-5-6$ fused ring system.

with the Li1/Li1' atoms connecting the two symmetrically equivalent benzotriazole frameworks through their N2N3/N3'N2' junctions. External Li2/Li2' atoms, more sterically accessible enabling greater THF solvation, lie either side of the fused ring plane as do the amido atoms (N4/N4'). Both the 1-phenyl and 4phenyl ring planes twist out of the fused ring plane by $39.05(6)$ and $46.17(7)^{\circ}$ respectively to which they are attached (via N1 and $\mathrm{C} 2$ respectively), while the second phenyl ring of the amido unit lies more remote but overhangs slightly with the fused ring core. Key bond dimensions are given in the legend to Figure 1. The Li-N bond lengths span the narrow range, 2.087(5) $2.140(5) \AA$, as the anionic (N4) or dative (N2, N3) nature of the bonding is offset by the different hybridisations involved (N2, N3, $\mathrm{sp}^{2} ; \mathrm{N} 4, \mathrm{sp}^{3}$ ). Similar Li-N (azole) bond lengths [1.992(5) $\AA$; $2.044(5) \AA]$ are encountered in the dimeric $\mathrm{N}$-lithiated benzotriazole iron(II) amide co-complex $\left[\left\{\mathrm{Li}(\text { bta }) \mathrm{Fe}(\mathrm{HMDS})_{2}\right\}_{2}\right]$ (HMDS=1,1,1,3,3,3-hexamethyldisilazide), [11] a close analogy of 2 as evidenced by its same 6-5-6-5-6 fused ring centrepiece (Figure 3). Interestingly, this bimetallic structure was interpreted in the context of the ring-laddering principle conceived by Snaith and Wade on the basis of their seminal studies of lithium amide structures. ${ }^{[12]}$ Thus it was interpreted as an iron amide intermolecularly intercepted dimeric unit of polymeric $\left[\{\mathrm{DMSO} \cdot \mathrm{Li}(\mathrm{bta})\}_{\infty}\right](\mathrm{DMSO}=$ dimethylsulfoxide $),{ }^{[13]}$ an infinite ladder structure characterised crystallographically by Schleyer (Figure 3). The 6-5-6-5-6 fused ring motifs also present in 
a)

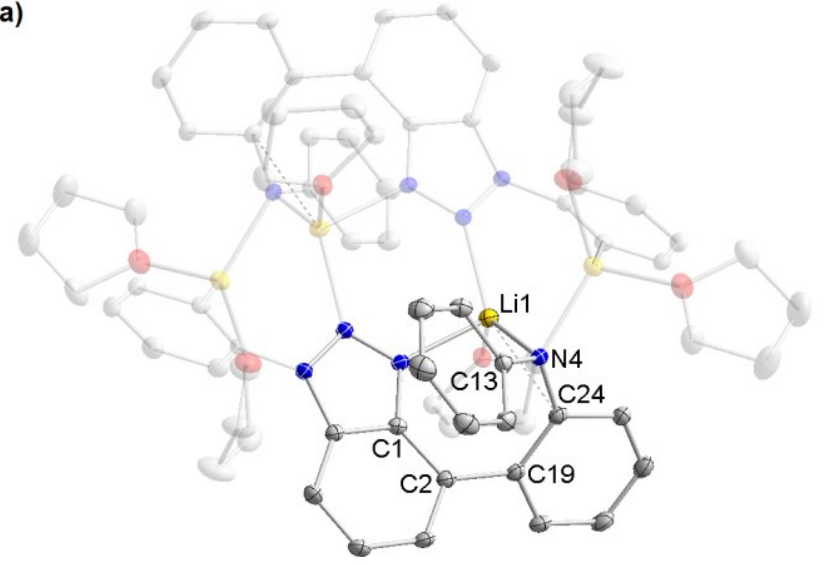

b)

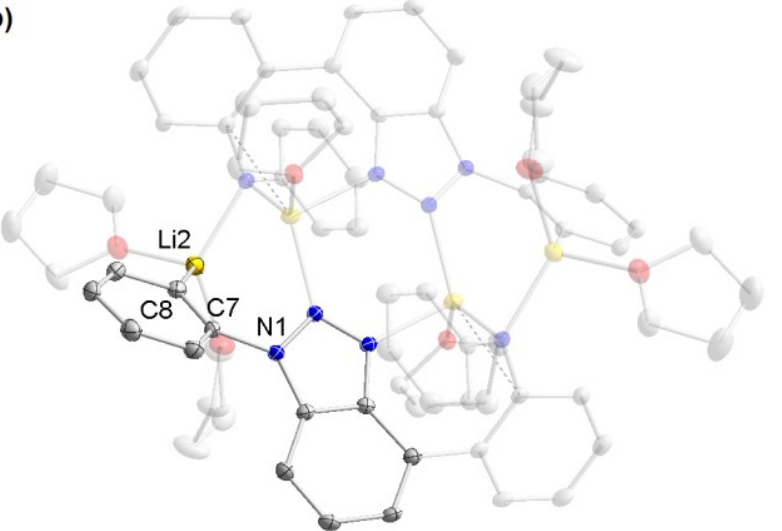

Figure 2. Views of $\mathbf{2}$ highlighting the new bonds constructed on the benzotriazole scaffold, namely the C2-C19 bond (a) and the Li2-C8 bond (b).

[\{DMSO-Li(bta) $\left.\}_{\infty}\right]$ join up in a head-to-tail arrangement with a (LiNNLiNN) $)_{\infty}$ ladder running through the centre of the polymer. Significantly, switching the alkali metal from lithium to potassium in $\left[\{\mathrm{HMPA} \cdot \mathrm{K}(\mathrm{bta})\}_{\infty}\right]^{[14]}$ (HMPA = hexamethylphosphoramide) maintains the polymeric ladder constitution though the single 6membered (LiNNLiNN) repeating unit is replaced by alternating, fused $(\mathrm{KN})_{2}$ rhomboids and $\left(\mathrm{KN}_{2}\right)$ triangles (Figure 3 ). Clearly the ring-laddering principle is less relevant to the structure of 2 since the diphenylamidolithium and phenyllithium grafts attached to the parent benzotriazole skeleton prevent aggregation higher than dimerization and the smallest ladder structure in the concept is a four-rung $(\mathrm{LiN})_{4}$ tetramer (that is, lateral association of two dimeric rings).

Mechanistic considerations: The most interesting aspect of the composition and structure of $\mathbf{2}$ is what they infer about its possible mechanism of formation. Two features stand out. First, the new $\mathrm{C} 2-\mathrm{C} 19$ bond that creates the biphenyl unit, and second the diphenylamido function which, originating from a 1-phenyl$1 \mathrm{H}$-benzotriazole molecule implies a dinitrogen $\left(\mathrm{N}_{2}\right)$ extrusion has taken place. Scheme 2 shows a plausible mechanism that can account for these events. Starting from a monodeprotonated derivative of 1 with the carbanionic centre located at the 4-position of the benzo ring (consistent with Mongin's in situ zinc study), ${ }^{[5]}$ if the formation of this monolithium complex is

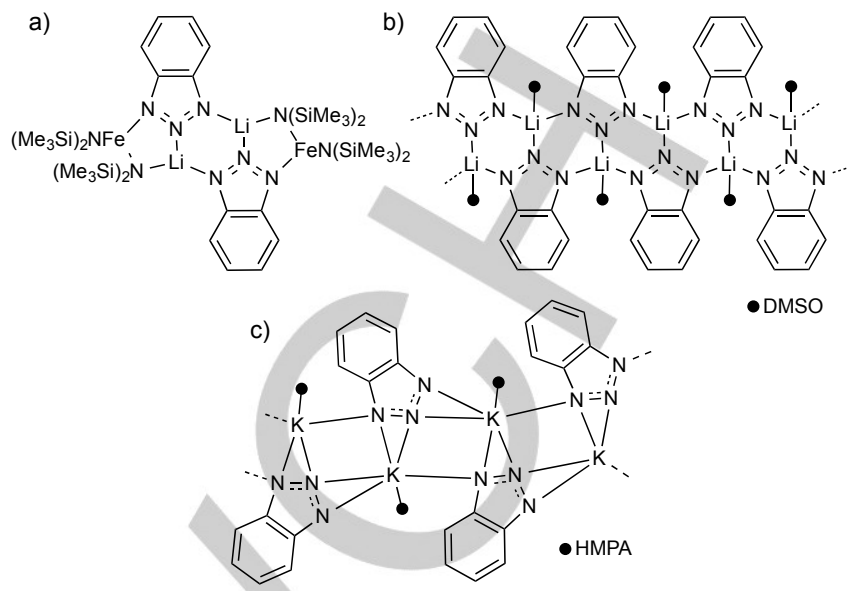

Figure 3. ChemDraw representations of (a) $\left[\left\{\mathrm{Li}(\mathrm{bta}) \mathrm{Fe}(\mathrm{HMDS})_{2}\right\}_{2}\right]{ }^{[11]}$ (b) $\left[\{\mathrm{DMSO} \cdot \mathrm{Li}(\mathrm{bta})\}_{\infty}\right]^{[13]}$ and (c) $\left[\{\mathrm{HMPA} \cdot \mathrm{K}(\mathrm{bta})\}_{\odot}\right]{ }^{\left[{ }^{[14]}\right.}$

slow then it in turn can react with non-metalated molecules of starting material 1. Nucleophilic attack of the ipso-sp ${ }^{2} \mathrm{C}$ bonded to $\mathrm{N} 1$ by this carbanion will induce extrusion of $\mathrm{N}_{2}$ to create an attached diphenylamido function. Since the reaction solution contained two equivalents of LiTMP per benzotriazole molecule, excess base is available to lithiate the 1-phenyl substituent under DoM control to give the isolated product $\mathbf{2}$. Alternatively the second TMP lithiation could have taken place at the onset of the reaction prior to the nucleophilic substitution/dinitrogen extrusion process. The conclusion from this part of the study is that LiTMP lithiation under the ambient temperature conditions studied is as anticipated ineffectual. The unsupported (in the sense of not having bimetallic synergistic stabilisation, see below) highly polar lithio intermediates are unstable and can undergo heterocycle-destroying side reactions. One such side reaction has been described here but given that the isolated yield of the product was only about $10 \%$ and the NMR spectra of reaction filtrates were unclean showing starting material, $\mathbf{2}$ and other unidentified products, it can be assumed that other side reactions are taking place.

Deprotolithiation with trans-metal-trapping via an aluminium protocol: We repeated the LiTMP lithiation of 1 but this time in the presence of the dialkylaluminium amide $i \mathrm{Bu}_{2} \mathrm{Al}(\mathrm{TMP})$. Due to the considerable steric bulk of both metal compounds they do not form an aluminate " $\left[\mathrm{Li}^{+}\left\{i \mathrm{Bu}_{2} \mathrm{Al}(\mathrm{TMP})_{2}\right\}\right]^{-}$", [8] so LiTMP is free to deprotonate the triazole (note TMP-aluminates have been found to be weak bases compared to lithium bases, generally incapable of deprotonating $\mathrm{C}-\mathrm{H}$ bonds). The reaction was carried out in two different stoichiometries with one or two molar equivalents of the base mixture to one equivalent of the triazole (Scheme 3). Mono- and di-deprotonation respectively were expected. In practice, only monodeprotonation was observed under either stoichiometry, but interestingly this was manifested in two distinct crystalline solids.

Established by X-ray crystallography, the formula of the minor product is $\left[\left(4-R^{\prime}-1 \text {-phenyl-1H-benzotriazole }\right)_{2}\right], \quad 3$ where $\mathrm{R}^{\prime}=i \mathrm{Bu}_{2} \mathrm{Al}(\mu-\mathrm{TMP}) \mathrm{Li}$. This $\mathrm{C}_{2}$ symmetric dimeric structure was produced from a 1:1, benzotriazole:base stoichiometric reaction. 


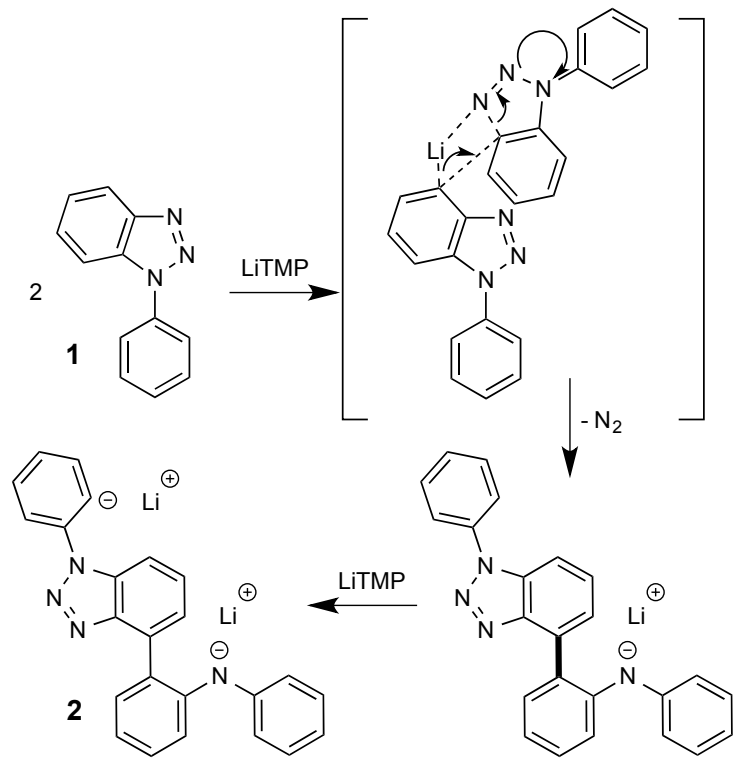

Scheme 2. Possible mechanism for the LiTMP-induced transformation of 1 phenyl-1H-benzotriazole 1 into the partially ring-opened product 2
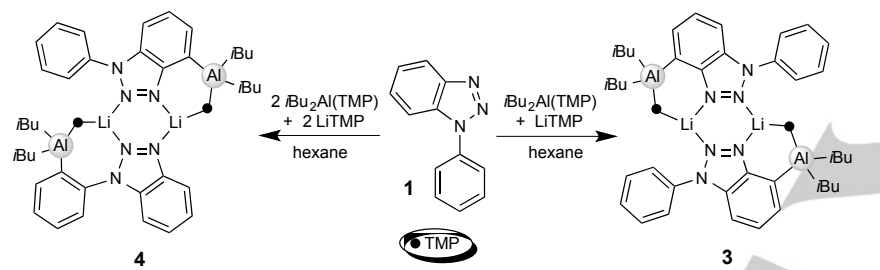

Scheme 3. Lithiation/trans-metal-trapping of 1 showing isolated crystalline products obtained.

Its classification as the minor (isolable) product reflects that it was isolated only from one reaction, whereas several repeated attempts under seemingly identical conditions afforded the major product, the heterodimeric isomer of $3,\left[\left(4-R^{\prime}-1-\right.\right.$ phenyl-1Hbenzotriazole)\{1-(2-R'-phenyl)-1H-benzotriazole\}], 4. With respect to the starting material $\mathbf{1}$, a single deprotonation has taken place at the 4-position of the benzo ring (C5) and two identical molecules have joined up to form the homodimeric structure of 3 (Figure 4). One of these benzo-deprotonated molecules forms one half of $\mathbf{4}$ with the other half a molecule of 1 selectively deprotonated at the ortho position of the phenyl ring (C12) to complete the tetranuclear (2xAl; $2 x \mathrm{Li})$ structure (Figure 5). Formally these deprotonations are aluminations ( $\mathrm{C}-\mathrm{H}$ to $\mathrm{C}-\mathrm{Al}$ exchanges) as in both $\mathbf{3}$ and $\mathbf{4}$ the deprotonated $\mathrm{C}$ atoms bond to Al through C5-Al1 and C12-Al1/C49-Al2 respectively, with the coordination sphere of each $\mathrm{Al}$ atom completed by two $i \mathrm{Bu}$ ligands and a $\mathrm{N}$ atom from TMP which bridges to Li. Within the monomeric moiety of $\mathbf{3}$ the Li atom bonds to TMP (Li1-N4) and the outer unsubstituted triazole $\mathrm{N}$ (Li1-N3), with the dimerization connection being to the central triazole $\mathrm{N}$ (Li1-N2') to complete a distorted trigonal planar $(\mathrm{N} \times 3)$ lithium coordination. Though the two distinct $\mathrm{Li}$ atoms in $\mathbf{4}$ also coordinate to $3 \mathrm{~N}$ atoms they do it differently from that in $\mathbf{3}$ and from each other. Thus, Li1 binds to two central triazole $\mathrm{N}$ atoms (Li1-N2, Li1-N6) and a TMP N (Li1$\mathrm{N} 4$ ); whereas Li2 binds to two unsubstituted outer triazole $\mathrm{N}$

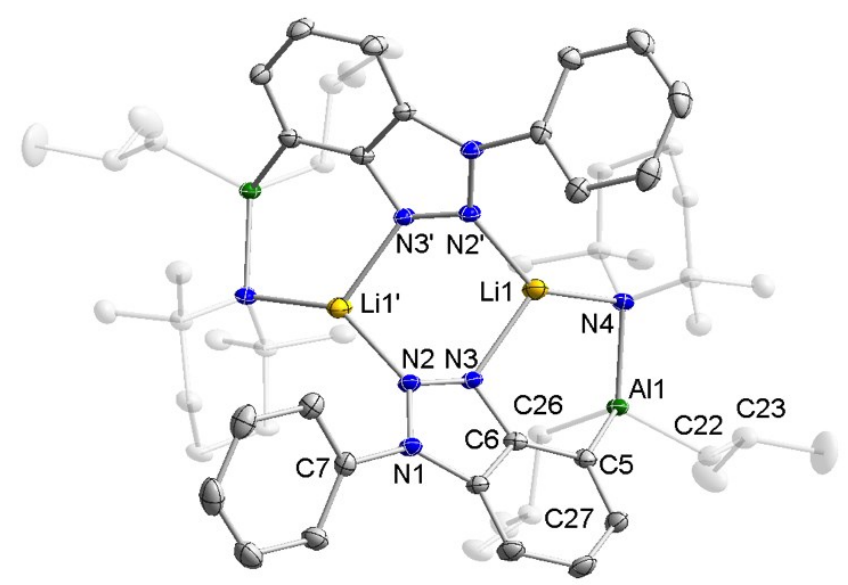

Figure 4. Molecular structure of [(4-R'-1-phenyl-1H-benzotriazole $\left.)_{2}\right]$ $\left[\mathrm{R}^{\prime}=i \mathrm{Bu}_{2} \mathrm{Al}(\mu-\mathrm{TMP}) \mathrm{Li}\right], 3$. Thermal ellipsoids are displayed at $35 \%$ probability, hydrogen atoms and one disordered methylcyclohexane molecule of crystallization have been omitted for clarity. Symmetry operation to generate equivalent atoms denoted ': $1-\mathrm{x}, \mathrm{y}, 1.5-\mathrm{z}$. Selected bond lengths $(\AA)$ and bond angles ( ${ }^{\circ}$ : Li1-N2', 2.075(4); Li1-N3, 2.035(4); Li1-N4, 2.028(4); Al1-N4, 1.9742(19); Al1-C5, 2.047(2); Al1-C22, 2.003(3); Al1-C26, 2.013(3); N1-N2, 1.359(2); N2-N3, 1.307(2); N1-C7, 1.432(3); N2'-Li1-N3, 95.65(18); N2'-Li1N4, 145.4(2); N3-Li1-N4, 119.0(2); Li1-N4-Al1, 100.15(13); Li1-N3-N2, 127.79(18); Li1-N2'-N3', 105.21(17); Li1-N2'-N1', 143.51(18); Li1-N3-C6, 111.18(18); N4-Al1-C5, 106.65(9); N4-Al1-C22, 116.94(10); N4-Al1-C26, 114.72(10); C22-Al1-C26, 109.21(12); C22-Al1-C5, 105.36(11); C26-Al1-C5, 102.46(10); Al1-C5-C6, 120.73(17); Al1-C22-C23, 121.45(19); Al1-C26-C27, 117.28(18); N1-N2-N3, 108.46(17); N3-C6-C5, 126.6(2).

atoms (Li2-N3, Li2-N7) and a TMP N (Li2-N8), with Li1-N6 and Li2-N3 connecting the two distinct monomeric, dinuclear moieties. Though all three structures 2, $\mathbf{3}$ and $\mathbf{4}$ share the same 6-5-6-5-6 fused ring core, conformationally these cores are distinct (Figure 6 shows a superimposition of the three cores). The fused ring core of $\mathbf{2}$ has an essentially planar, linear-ladder shape in contrast to those of $\mathbf{3}$ and $\mathbf{4}$ which are severely puckered. In $\mathbf{4}$ it is butterfly shaped with a Li...Li hinge and benzotriazolyl wings whose planes lie at $50.90(4)^{\circ}$ to one another, whereas in $\mathbf{3}$ one of the benzotriazole rings is almost perpendicular relative to the other at $86.94(4)^{\circ}$. These conformational contrasts are a consequence of the different coordinations at the $\mathrm{Li}$ junctions which connect the two benzotriazolyl frameworks, coupled with the different substitution patterns within these frameworks. In 3 the 1-phenyl substituents project mainly above the $6-5-6-5-6$ fused ring core while the $i \mathrm{Bu}_{2} \mathrm{Al}(\mathrm{TMP})$ units are situated below it. In 4 the deprotonated phenyl ring lies twisted with respect to the triazole ring to which it is attached $\left[49.61(6)^{\circ}\right]$, while the inclination of the nondeprotonated phenyl ring is marginally less at $44.21(6)^{\circ}$. As in 3 , the $\mathrm{Bu}_{2} \mathrm{Al}(\mathrm{TMP})$ units are situated for the most part underneath the fused ring core which as a consequence of steric restraint must bend upwards in contrast to its near planar disposition in $\mathbf{2}$. To the best of our knowledge there are no previous examples of $\mathrm{C}-\mathrm{H}$ aluminated benzotriazolyl-based crystal structures for direct comparison with $\mathbf{3}$ and $\mathbf{4}$. Benzotriazole derivatives substituted by phenol appendages at the $2 \mathrm{H}-\mathrm{N}$ position have been structurally determined but these do not contain $\mathrm{Al}-\mathrm{C}$ bonds as their $\mathrm{Al}$ centres interact only with $\mathrm{N}$ and $\mathrm{O}$ atoms. ${ }^{[10]}$ All the $\mathrm{Al}-\mathrm{C}$ bonds within 3 and $\mathbf{4}$ fall in the narrow range 2.003(3) - 2.101(2) $\AA$. The mean Al-C $(i-B u)$ bond length $(2.0127 \AA)$ is in the range of 


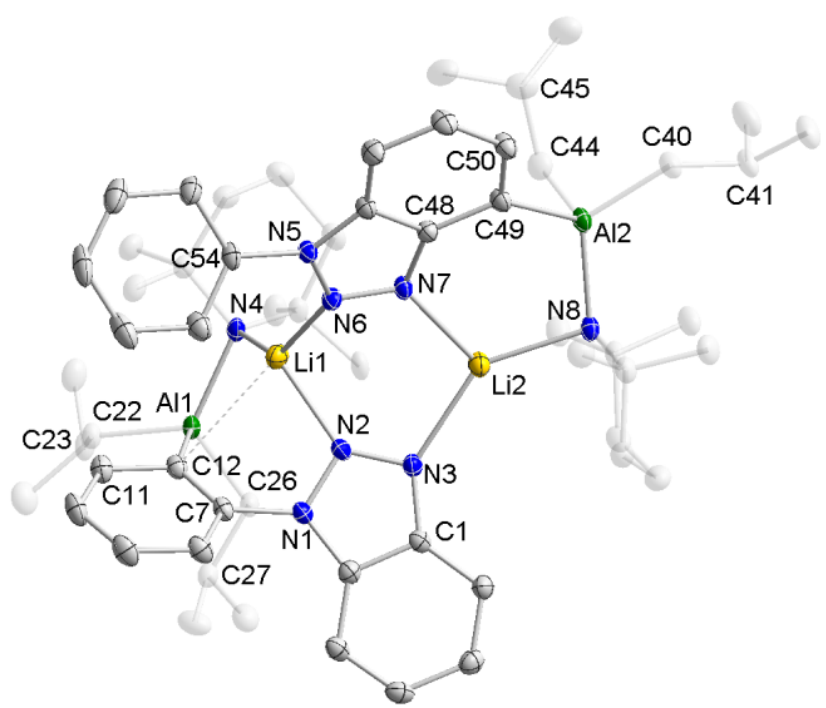

Figure 5. Molecular structure of [(4-R'-1-phenyl-1H-benzotriazole)\{1-(2-R'phenyl)- $1 H$-benzotriazole $\}],\left[R^{\prime}=i \mathrm{Bu}_{2} \mathrm{Al}(\mu-\mathrm{TMP}) \mathrm{Li}\right], 4$. Thermal ellipsoids are displayed at $35 \%$ probability, hydrogen atoms, one disordered component of $i \mathrm{Bu}$ and one $n$-hexane molecule of crystallization have been omitted for clarity. The dashed lines illustrate Li $\cdots C$ contact: Li1 $\cdots C$ C12, 2.695(4). Selected bond lengths $(\AA)$ and bond angles $\left({ }^{\circ}\right)$ : Li1-N2, 2.064(4); Li1-N4, 2.048(4); Li1-N6, 2.053(4); Li2-N3, 2.195(4); Li2-N7, 2.083(4); Li2-N8, 2.094(4); Al1-C12, 2.101(2); Al1-N4, 1.9659(19); Al1-C22, 2.015(2); Al1-C26, 2.020(2); Al2-C49, 2.037(2); Al2-N8, 1.9748(19); Al2-C40, 2.008(2); Al2-C44, 2.014(2); N2-Li1-N4 122.9(2); N2-Li1-N6, 91.55(16); N4-Li1-N6, 134.6(2); Li1-N4-Al1, 90.76(13); Li1-N2-N1, 114.49(16); Li1-N2-N3, 135.37(17); Li1-N6-N7, 116.01(17); Li1-N6N5, 132.73(16); N3-Li2-N7, 103.68(16); N3-Li2-N8, 141.02(19); N7-Li2-N8, 113.95(19); Li2-N8-Al2, 103.70(13); Li2-N3-N2-, 110.12(16); Li2-N3-C1, 139.65(17); Li2-N7-N6, 126.50(17); Li2-N7-C48, 119.90(17); N4-Al1-C12, 105.74(8); C22-Al1-C12, 103.71(9); C26-Al1-C12, 105.41(9); C22-Al1-C26, 103.12(10); C22-Al1-N4, 119.38(9); C26-Al1-N4, 117.88(8); Al1-C12-C7, 131.38(15); Al1-C12-C11, 114.33(16); Al1-C22-C23, 119.84(15); Al1-C26-C27, 115.95(14); N8-Al2-C49, 107.63(8); C40-Al2-C49, 102.76(10); C44-Al2-C49, 100.74(9); C40-Al2-C44, 110.60(11); N8-AI2-C40, 118.03(10); N8-Al2-C44, 114.77(9); Al2-C49-C48, 123.62(16); Al2-C49-C50, 124.03(16); Al2-C40-C41, 124.81(17); Al2-C44-C45, 109.4(4); N1-N2-N3, 109.49(16); N5-N6-N7, 108.64(17); N2-N1-C7, 119.47(17); N6-N5-C54, 119.16(17); N7-C48-C49, 127.76(18).

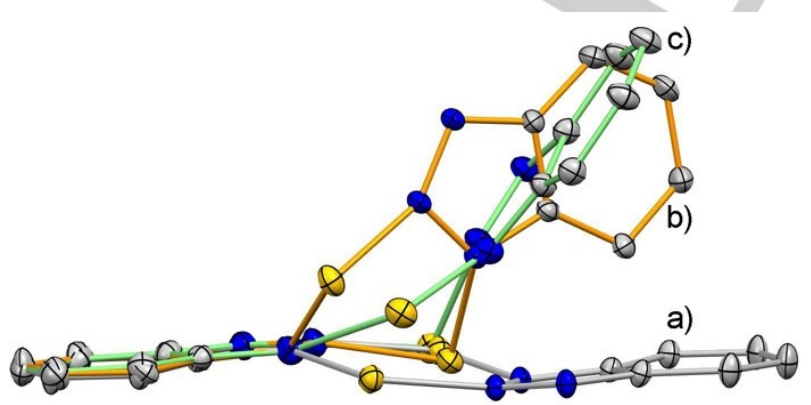

Figure 6. Superimposition of the 6-5-6-5-6 fused ring cores of (a) complex 2 (b) complex 3 and (c) complex 4. Blue ellipsoids represent nitrogen atoms and yellow ellipsoids represent lithium atoms. other 4-coordinate Al centres bound to iso-butyl ligands in lithium aluminate structures (for example in $\left[\left\{i \mathrm{Bu}_{2} \mathrm{Al}(\mathrm{NPh}) \mathrm{Li} \cdot \mathrm{THF}\right\}_{2}\right],{ }^{[15]}$ mean, $2.0085 \quad \AA ; \quad$ in $\left[\left\{\mathrm{PhC}(=\mathrm{O}) \mathrm{NiPr}_{2}\right\} \mathrm{Li}(\mathrm{TMP})(\mathrm{BBu}) \mathrm{Al}(\mathrm{BBu})_{2}\right],{ }^{[16]}$ mean terminal bond length, $2.034 \AA$ ). Little variation is found in the Al-N(TMP) bonds within 3 and 4 with a mean length of $1.9716 \AA$. The Li-N(TMP) bonds span 2.028 - 2.094(4) $\AA$, while the Li-N(triazolyl) bonds span 2.035(4) - 2.195(4) $\AA$ with longest bond [2.195(4) $\AA]$ belonging to the monomer connecting $\mathrm{Li}(2)-\mathrm{N}(3)$ junction in complex 4.

NMR spectroscopic studies of the lithium aluminate systems: Full details and copies of the NMR spectra of the new compounds 3-4 are provided in the Supporting Information. It was not possible nor indeed considered worthwhile to assign the resonances for the LiTMP induced benzotriazolyl ring-opening product 2 because it was clearly formed as a mixture of crystallographically characterised $\mathbf{2}$, starting material and at least one unknown species.

The homodimer 3 was characterised by both ${ }^{1} \mathrm{H}$ and ${ }^{13} \mathrm{C}$ NMR spectra recorded in $\mathrm{C}_{6} \mathrm{D}_{6}$ solution. Though the spectra are complicated and several resonances overlap, with the help of 2D NMR experiments (COSY, HSQC and HMBC experiments) we were able to assign all of the expected resonances. An interesting feature is that, although the structure in the solid state contains only one type of TMP ligand, the ${ }^{1} \mathrm{H}$ resonances associated with it in solution consist of two $\gamma \mathrm{CHH}^{\prime}$ (at $1.57 \mathrm{ppm}$ and $0.87-0.70 \mathrm{ppm}$ ), two $\beta \mathrm{CH} H^{\prime}$ (at 1.12-0.98 ppm and 0.29 ppm) and two $\mathrm{CH}_{3}$ resonances (at $1.57 \mathrm{ppm}$ and 1.12-0.98 ppm), a pattern which fits with the five TMP resonances observed in the ${ }^{13} \mathrm{C}$ NMR spectrum. This suggests the TMP ligand is held rigidly in an asymmetrical arrangement, which is consistent with its bridging placement between the $\mathrm{Li}$ and $\mathrm{Al}$ centres in the crystal structure of 3 . The highest frequency resonance in the ${ }^{1} \mathrm{H}$ spectrum at $8.30 \mathrm{ppm}$ can be assigned to the $\mathrm{C}-\mathrm{H}$ on the benzo ring adjacent to the $\mathrm{C}-\mathrm{Al}$ bond (its associated $\mathrm{C}-\mathrm{H}$ resonance comes at $135.8 \mathrm{ppm})$. While we could not observe the $C$-A resonance directly in the ${ }^{13} \mathrm{C}$ NMR spectrum, we found it at $162.1 \mathrm{ppm}$ through a ${ }^{1} \mathrm{H},{ }^{13} \mathrm{C}-\mathrm{HMBC}$ experiment.

Assigning and interpreting the ${ }^{1} \mathrm{H}$ and ${ }^{13} \mathrm{C}$ NMR spectra for the heterodimeric lithium aluminate 4 proved more of a challenge due to the inherently greater complexity of the data. The causes of this were a combination of the structural asymmetry of $\mathbf{4}$ and the existence of a slow chemical exchange process. We elected to interrogate the NMR signal assignments and the structure and dynamics for 4 using a battery of 1- and 2-dimensional NMR techniques. The slow-exchange (on the chemical shift NMR timescale) dynamics were notably evident through the occurrence of strong exchange cross-peaks in $2 \mathrm{D}\left[{ }^{1} \mathrm{H},{ }^{1} \mathrm{H}\right]$ EXSY NMR data and detected by ${ }^{1} \mathrm{H}$ resonance lineshape variation over a range of temperatures either side of ambient. Critically, no exchange cross-peaks were detected in the aromatic resonance region of the $2 \mathrm{D}\left[{ }^{1} \mathrm{H},{ }^{1} \mathrm{H}\right]$ EXSY NMR data. This ruled out a see-saw chemical bond-making and breaking process within the heterodimer complex and led us to consider other alternative explanations. Exchange cross-peaks occurring solely within the aliphatic proton resonance range led us to surmise 
that slow conformational flexibility was the most likely source of these observations. To quantify the process, a series of temperature-dependent $2 \mathrm{D}\left[{ }^{1} \mathrm{H},{ }^{1} \mathrm{H}\right]$ EXSY NMR data sets were acquired for 4 in the temperature range $263 \leq T \leq 323 \mathrm{~K}$ at mixing times varying in the range $5 \leq \tau_{\mathrm{m}} \leq 200 \mathrm{~ms}$ (see Supporting Information). The data gave activation enthalpy $\square H^{\ddagger}$ $=71 \pm 5 \mathrm{~kJ} \mathrm{~mol}^{-1}$, Gibbs free energy of activation at $298 \mathrm{~K}$, $\square G^{\ddagger}{ }_{298}=67 \pm 5 \mathrm{~kJ} \mathrm{~mol}^{-1}$ and activation energy $E_{\mathrm{a}}=75.4 \pm 0.4 \mathrm{~kJ}$ $\mathrm{mol}^{-1}$, values that are consistent with conformational rearrangement dynamics rather than bond breaking and making. To explore more closely the conformations and to firmly establish the nature of the solution-phase species representing 4 we made strides towards assigning the data to allow key through-space information, acquired via $2 \mathrm{D}\left[{ }^{1} \mathrm{H},{ }^{1} \mathrm{H}\right] \mathrm{NOESY}$ NMR data, to be interpreted.

For this we acquired NMR data on a sample of $\mathbf{4}$ in toluene- $d_{8}$ cooled to $213 \mathrm{~K}$, at which temperature the exchange process was sufficiently arrested to ensure that the NOESY data were dominated by genuine NOEs, exchange cross-peaks being suppressed below the level of detection. With the assignment of the aromatic proton resonances confirmed at this temperature, we used these and the representative crystal structure of $\mathbf{4}$ to determine the most likely NOE cross-peak assignments.
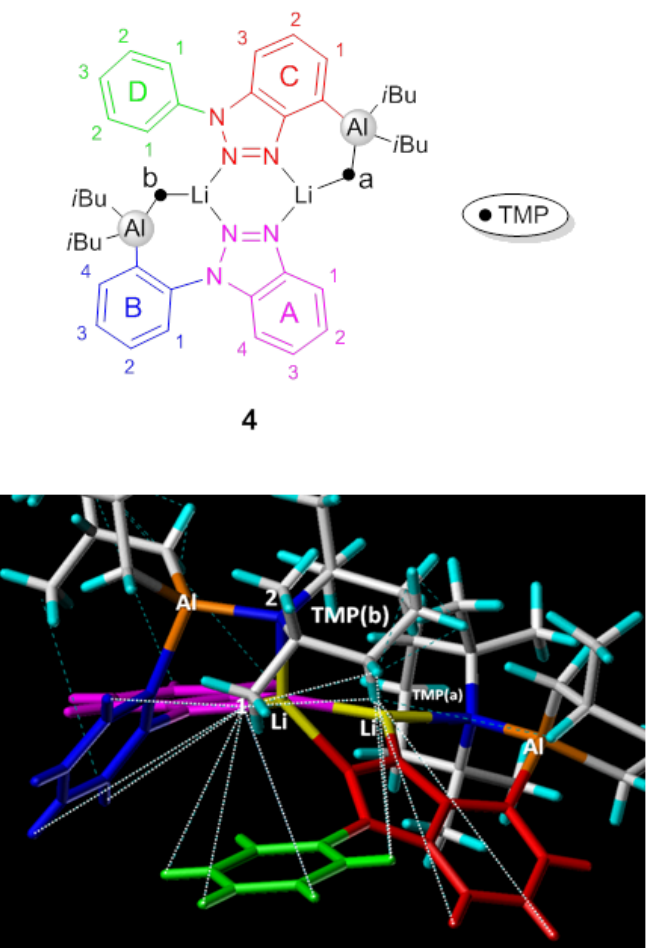

Figure 7. Colour coded chemical structure of 4 [TOP]; NOEs shown mapped onto a representative structure of $\mathbf{4}$ having the same colour coding [BOTTOM]. NOEs are shown for protons of the TMP(b)-methyl-1 group plus the adjacent TMP(b)-methylene $a / b$ protons to the surrounding aromatic residue protons (white dashed lines).
The complexity of the data meant that specific, unambiguous assignments were not easily obtained from the NOE data for 4. However, it was possible to identify NOEs that were associated specifically with one of the four methyl groups (methyl-1) of the TMP moiety designated here as TMP(b) whose nitrogen centre is identified as N4 in Figure 5. The NOEs, shown in Figure 7 as white dotted lines, occurred between the methyl-1 protons and those protons of the aromatic rings lying in close proximity as indicated in the Figure and provided in Table S2 of the Supporting Information.

As shown (Supporting Information Fig S7), the proton resonance arising from the NMR-assigned $\operatorname{TMP}(b)$ methyl group has two identities at low temperature related by chemical exchange and whose chemical shift separation $\Delta \delta=1.0 \mathrm{ppm}$. The conformation shown in Fig. 7, allows the NOEs arising from the proton resonance of the methyl group at $\delta^{1} \mathrm{H}=0.6 \mathrm{ppm}$ to be assigned. The relatively low chemical shift is consistent with magnetic shielding: here the TMP(b) methyl group is located above an aromatic ring plane as shown in Fig. 7. By extension, it follows that the same methyl group can also be located in a less shielded environment $\left(\delta^{1} \mathrm{H}=1.6 \mathrm{ppm}\right)$ through conformational exchange. By implication, this suggests that the conformational flexibility revealed by the NMR data of $\mathbf{4}$ in solution is associated with movement within the structure that relocates $\operatorname{TMP}(b)$ methyl-1. This could be readily achieved through a conformational change in the 7-membered ring containing the $\mathrm{TMP}(\mathrm{b})$ nitrogen centre (N4 in Figure 5) which would be consistent with the thermodynamic quantities obtained by exchange data analysis. This is more likely than the equivalent conformational rearrangement of the 6-membered ring containing the $\operatorname{TMP}(\mathrm{a})$ nitrogen centre (N8 in Figure 5). Such a process would require the climbing of higher energy than the one determined by our exchange data analysis. Other large proton chemical shift changes were identified that arise by the same process, but unambiguous assignment of these signals was not possible. NMR resonances from groups closely related to TMP(b)-methyl-1 were also affected in a similar manner on the basis of which it is proposed that the dynamic event observed for 4 in solution is concerted motion of the 7membered ring N4-Li1-N2-N1-C7-C12-Al1 (Figure 5).

Consideration of these same NOE data confirms that the molecule exists as the intact heterodimer when in solution. The simultaneous appearance of NOEs to TMP(b)-methyl- 1 protons from the aromatic proton resonances of both of the 6-membered aromatic rings attached to each benzotriazole shows that the two halves of the complex are in close proximity to the identified $\mathrm{TMP}(\mathrm{b})$ methyl group, allowing NOEs to evolve from both sides of the molecule simultaneously.

Deprotozincation via a lithium-zinc base mixture: The logical starting point for this part of our investigation was to follow Mongin's original literature preparation (see Scheme 1 in the introduction). ${ }^{[5]}$ A quantitative (99\%) yield of the 4,2'-diiodo derivative of 1 was reported on mixing 1 with three equivalents of $\operatorname{TMP}(\mathrm{H}) / n \mathrm{BuLi}$ (i.e., in situ LiTMP) and one equivalent of $\mathrm{ZnCl}_{2} \cdot \mathrm{TMEDA}$ in THF solution at room temperature for two hours followed by quenching with three equivalents of the 
electrophile iodine. From other literature on this base mixture it is certain that a lot of chemistry is concealed in the reaction coordinate between reactant 1 and the final 4,2'-diiodo product. Intuitively one might expect that the base mixture would undergo a complete metathesis to generate the ate "LiZn(TMP) $)_{3}$ "[17] especially as ate reagents have been fundamental to many of the recent advances made in metalation chemistry. However, DOSY NMR data in the reaction solvent (THF) point to an alternative partial metathesis terminating at neutral, weakly basic $\mathrm{Zn}(\mathrm{TMP})_{2}$, with "LiZn(TMP) $)_{3}$ " forbidden on steric grounds, leaving LiTMP (or a co-complexed/solvated version) ${ }^{[18]}$ as the only starting base in the mixture strong enough to $\mathrm{C}-\mathrm{H}$ deprotonate a benzotriazole. Following deprotonation of presumably the benzo-4 position (using less base Mongin $[5]$ found that this regioselectivity was greatly favoured), the lithiated benzotriazole could undergo transmetalation with $\mathrm{Zn}(\mathrm{TMP})_{2}$ to make a monozincated benzotriazole and LiTMP (Scheme 4). In turn, this second LiTMP can deprotonate the ortho-2' position of the phenyl substituent to form the dideprotonated, mixed lithiumzinc benzotriazole. Two possible scenarios can be envisaged from here to reach the diiodo product. Either this mixed lithiumzinc species could be iodinated directly or alternatively its $\mathrm{Li}$ centre could undergo a fast second transmetalation to form a zinc dianionic benzotriazolate and LiTMP prior to iodination. Endeavours to gather experimental evidence that would shed light on the above possibilities have proved frustratingly challenging. We have made several attempts to obtain crystalline or solid forms of possible metalo intermediates by following this literature procedure ${ }^{[5]}$ but omitting the final iodination step. The excellent solubility of the metal intermediate/s in THF solution has hampered this quest. Even cooling the reaction solution to $-33^{\circ} \mathrm{C}$ failed to induce the deposition of any solid. This is noteworthy since the mixture contains lithium chloride, at least formally, though the aforementioned DOSY study proposed the possibility that this metathetical coproduct might not be free but is incorporated within the active lithiating base of formula LiTMP.2LiCl \pm TMEDA. With few exceptions it is notoriously difficult to crystallise metalo complexes from THF solutions of reaction mixtures containing salt-supported organometallic bases. ${ }^{[19]}$ In this case we enjoyed a modicum of success as setting the reaction solution aside at room temperature for about a month produced a tiny crop of very small crystals which, when subjected to an X-ray crystallographic study, proved to be only weakly diffracting. The poorly diffracting nature of the crystals is undoubtedly correlated to large amounts of disorder in two separate major structural features. Disordered, THF solvated $\mathrm{Li}^{+}\left(\mathrm{C}_{4} \mathrm{H}_{7} \mathrm{O}\right)^{-}$centres (that is metallated THF anions) are present at approximately half of the possible sites at the core of an ordered metallocycle while disordered THF present as "solvent of crystallisation" could only be treated by using the SQUEEZE routine implemented within PLATON to remove it from the structural model. ${ }^{[20]}$ Despite the poor quality of the data, the connectivity of the main structural feature is well-defined, comprising a hexameric ring of alternating $\mathrm{Zn}$ atoms and dideprotonated benzotriazole ligands with zinc bridging between the 4-position of one ligand and the 2 '-position of another (Figure 8), leading us to presume an

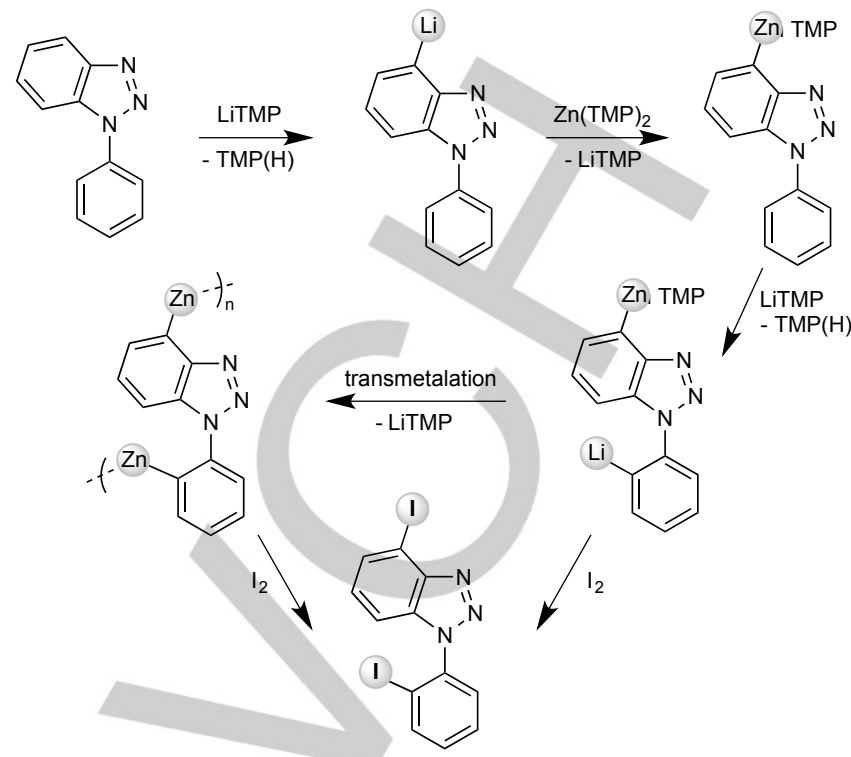

Scheme 4. Proposed mechanism for the formation of complex 5 and its subsequent iodination.

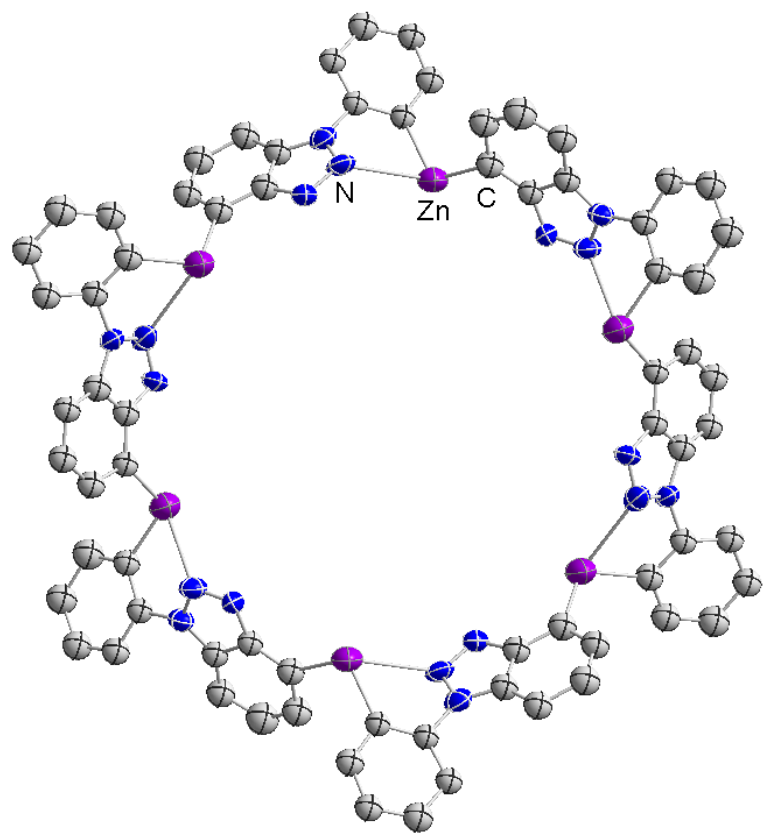

Figure 8. Proposed cyclic feature of a dizincated 1-phenyl-1H-benzotriazole intermediate $\mathbf{5}$ as suggested by a low resolution crystal structure determination.

approximate formula

of

$\left[\left\{\mathrm{C}_{6} \mathrm{H}_{3} \mathrm{~N}_{3}\left(\mathrm{C}_{6} \mathrm{H}_{4}\right) \mathrm{Zn}\right\}_{6}(\mathrm{Li})_{3}\left(\mathrm{C}_{4} \mathrm{H}_{7} \mathrm{O}\right)_{3}(\mathrm{THF})_{6}\right] \cdot n T H F$, 5. Though there is no evidence to say this species represents the bulk product of the reaction its $4,2^{\prime}$-dideprotonation matches up well with the 4,2'-diiodination observed by Mongin following the quenching step. Also it appears to concur with the second scenario mentioned above whereby zinc stabilises the two dideprotonated benzotriazole centres to release an equivalent of LiTMP, which, in turn, can deprotonate THF solvent molecules to generate $\mathrm{C}_{4} \mathrm{H}_{7} \mathrm{O}^{-}$anions. Deprotonative metalation of THF usually forces its ring opening and decomposition but significantly $\alpha$ - 
deprotonated THF anions $\left(\mathrm{C}_{4} \mathrm{H}_{7} \mathrm{O}^{-}\right)$can exist intact under bimetallic ( $\mathrm{Na}-\mathrm{Zn}$ or $\mathrm{Li}-\mathrm{Al})^{[21]}$ synergic stabilisation so a similar $\mathrm{Li}$ $\mathrm{Zn}$ effect could be in operation here. It is also pertinent to note that zincocyclic structures are known. For example, our own earlier work probing the alkali-metal-mediated zincation of $\mathrm{N}, \mathrm{N}$ diethyl-thiophene-2-carboxamide by the sodium zincate reagent $[(\mathrm{TMEDA}) \mathrm{Na}(\mathrm{TMP})(t \mathrm{Bu}) \mathrm{Zn}(t \mathrm{Bu})]^{[22]}$ produced a nice example of a 16-membered $(\mathrm{ZnCCC})_{4}$ ring. ${ }^{[23]}$ This smaller zincocycle is related to that in $\mathbf{5}$ as the ring arises from double deprotonation of the thiophene unit (compare that of the benzotriazole unit in 5), but in contrast it was produced via direct zincation $(\mathrm{Zn}-\mathrm{H}$ exchange) unlike the indirect lithiation/zinc-trapping mechanism at work in the synthesis of $\mathbf{5}$ (or the lithiation/aluminium-trapping in 3 and $\mathbf{4}$ ).

\section{Conclusions}

The aim of this study was to gain some structural comprehension of the metalation chemistry of heterocyclic substrates by complicated multicomponent organometallic bases. Studies of this type are essential to unravel the complexity of these base mixtures, which can often outperform single component bases such as LiTMP. Though excellent work by Mongin et al had quantified the yields and selectivities of the metalation of 1-phenyl-1 $\mathrm{H}$-benzotriazole with sequential in situ $\mathrm{ZnCl}_{2} \cdot \mathrm{TMEDA} / \mathrm{LiTMP}$ and iodine protocols, no information was gleaned on the reactive metalo intermediates, which mediate the iodine-hydrogen exchange reaction. As commonly found in mixed-metal base systems, extracting quality crystalline samples from bulk THF solutions is no straightforward task and that proved to be the case here though an incomplete crystal structure determination suggested a hexameric ring system where the zinc atoms bridge between dideprotonated benzotriazole molecules. More clarity was forthcoming on the new reactions with our $\mathrm{LiTMP} / \mathrm{BBu}_{2} \mathrm{Al}(\mathrm{TMP})$ trans-metal-trapping protocol. In the absence of the aluminium support, LiTMP promoted the lithiation of the triazole ring at the ortho-Ph substituent but effected the decomposition of another triazole ring to generate a diphenylamidolithium fragment with both fragments mutually attached through a new $\mathrm{C}-\mathrm{C}$ bond as evidenced via a structural determination of the isolated crystalline product. Adding $\mathrm{iBu}_{2} \mathrm{Al}(\mathrm{TMP})$ stabilised metalated benzotriazole preventing such a ring-opening decomposition, instead giving rise to two chemically and crystallographically distinct products. Both are isomeric lithium aluminates with the homodimer exhibiting deprotonation/alumination at the benzo-4 position only, while the other heterodimer exhibits deprotonation/alumination at the benzo-4 and ortho- $\mathrm{Ph}$ positions but in separate monomeric units which co-complex. On the basis of these findings, trans-metal-trapping with this or related nonco-complexing organometallic pairs could become a useful technique for stabilising other sensitive heterocycles.

\section{Experimental Section}

General procedures: All reactions and manipulations were performed under a protective atmosphere of dry pure argon gas using standard Schlenk tube or glovebox techniques. Solvents were dried by heating to reflux over sodium benzophenone ketyl and distilled under nitrogen prior to use. Deuterated NMR solvents were degasified and stored over $4 \AA$ molecular sieves prior to use. 2,2,6,6-tetramethylpiperidine $\mathrm{TMP}(\mathrm{H})$ was purchased from Merck $\mathrm{KGaA}$, and stored over activated $4 \AA$ molecular sieves. $n \mathrm{BuLi}$ (1.6 $\mathrm{M}$ in $n$-hexane solution), $\mathrm{AlCl}_{3}$ and $i \mathrm{Bu}_{2} \mathrm{AICl}$ were purchased from Aldrich and used as received. 1-Phenylbenzotriazole ${ }^{[24]}$ was prepared according to literature methods. LiTMP[25] and $i \mathrm{Bu}_{2} \mathrm{Al}(\mathrm{TMP})^{[26]}$ were prepared according to literature procedures. NMR spectra were recorded on a Bruker AVANCE 400 NMR spectrometer, operating at $400.1 \mathrm{MHz}$ for ${ }^{1} \mathrm{H}, 155.5 \mathrm{MHz}$ for ${ }^{7} \mathrm{Li}, 104.2 \mathrm{MHz}$ for ${ }^{27} \mathrm{Al}$ and 100.6 $\mathrm{MHz}$ for ${ }^{13} \mathrm{C}$. ${ }^{1} \mathrm{H}$ and ${ }^{13} \mathrm{C}\left\{{ }^{1} \mathrm{H}\right\}$ spectra were referenced to the appropriate solvent signal, ${ }^{7} \mathrm{Li}$ NMR spectra were referenced against $\mathrm{LiCl}$ in $\mathrm{D}_{2} \mathrm{O}$ at $0.00 \mathrm{ppm}$ and ${ }^{27} \mathrm{Al}$ NMR spectra were referenced against $\mathrm{AlCl}_{3}$ in $\mathrm{D}_{2} \mathrm{O}$ at $0.00 \mathrm{ppm}$. Elemental analyses of the compounds 3-4 were carried out using a Perkin Elmer 2400 elemental analyser.

Crystal structure determination: Single-crystal data were recorded at 123(2) $\mathrm{K}$ on Oxford Diffraction Gemini and Xcalibur Diffractometers with Mo-Ka $(\lambda=0.71073 \AA$, for $2-4)$ and $\mathrm{Cu}-K \alpha(\lambda=1.5418 \AA$, for 5$)$ radiation, respectively. The structures were refined to convergence on $F^{2}$ and against all independent reflections by full-matrix least-squares using SHELXL programs. [27] The crystallisation THF and methylcyclohexane molecules of $\mathbf{2}$ and $\mathbf{3}$, respectively, were modelled as disordered over two sites, as was one of the $i \mathrm{Bu}$ anions in 4 . The SQUEEZE routine within PLATON was used to remove approximately 125 electron equivalents from $936 \AA^{3}$ of unit cell volume of $5 . \underline{[20]}$ These are believed to correspond to further THF molecules. This low resolution structure would not support an anisotropic treatment of the $\mathrm{C}$ atoms. The geometries of the disordered groups were restrained to approximate typical values. Selected crystallographic parameters are given in Supporting Information. CCDC-1400385 (2), CCDC-1400386 (3), CCDC-1400387 (4) and CCDC1400388 (5) contain the supplementary crystallographic data for this paper. These data can be obtained free of charge from the Cambridge Crystallographic Data Centre via www.ccdc.cam.ac.uk/data request/cif.

Synthesis of [\{4-R-1-(2-lithiophenyl)-1H-benzotriazole-3THF $\left.\}_{2}\right]$, [R = 2- $\mathrm{C}_{6} \mathrm{H}_{4}(\mathrm{Ph}) \mathrm{NLi}$, 2. In a Schlenk tube, 1-phenyl-1H-benzotriazole (195 $\mathrm{mg}, 1 \mathrm{mmol}$ ) was suspended in $n$-hexane $(15 \mathrm{~mL})$ and LiTMP $(294 \mathrm{mg}, 2$ $\mathrm{mmol}$ ) was then added. The resulting yellow suspension was stirred for 2 $\mathrm{h}$ at room temperature. THF $(2 \mathrm{~mL})$ was then added and the reaction mixture was heated until a dark solution was achieved. The solution was placed in a freezer operating at $-15^{\circ} \mathrm{C}$. After a few days, crystals of 2 were obtained $(132 \mathrm{mg}, 0.10 \mathrm{mmol}, 10 \%)$. The ${ }^{1} \mathrm{H}$ NMR spectrum of the reaction shows that the metallation is not clean and that also there is starting material. ${ }^{1} \mathrm{H}$ NMR $(400.13 \mathrm{MHz}$, d8-THF, $300 \mathrm{~K})$ : $\delta 7.90-7.81(\mathrm{~m})$ 7.68-7.47 (m), $7.32(\mathrm{~m}), 7.08(\mathrm{~m}), 6.89(\mathrm{~d}, 2 \mathrm{H}), 6.70(\mathrm{t}, 1 \mathrm{H}), 3.60(\mathrm{~m}$, THF), $1.77 \mathrm{ppm}$ (m, THF). We observe by NMR spectroscopy a small amount of 1 -phenyl-1 $\mathrm{H}$-benzotriazole ${ }^{[28]}$ in the reaction. ${ }^{1} \mathrm{H}$-NMR $(400.13$ $\mathrm{MHz}, \mathrm{d}_{8}-\mathrm{THF}, 300 \mathrm{~K}$ ) of $\mathrm{C}_{12} \mathrm{H}_{9} \mathrm{~N}_{3}$ : $\delta 8.09$ ("dt", $1 \mathrm{H}, J=8.4 \mathrm{~Hz}, J=0.9 \mathrm{~Hz}$, $\left.H_{4}\right)$ ), $7.86\left(\mathrm{~m}, 3 \mathrm{H}, H_{7}, H_{2}, 6^{\prime}\right), 7.63\left(\mathrm{~m}, 2 \mathrm{H}, H_{\left.3^{\prime}, 5^{\circ}\right),} 7.55\right.$ (ddd, $1 \mathrm{H}, J=8.0 \mathrm{~Hz}$, $\left.J=6.9 \mathrm{~Hz}, J=1.0 \mathrm{~Hz}, H_{6}\right), 7.49\left(\mathrm{tt}, 1 \mathrm{H}, J=6.9 \mathrm{~Hz}, J=1.1 \mathrm{~Hz}, H_{4^{\prime}}\right), 7.41$ ppm (ddd, $1 \mathrm{H}, J=8.2 \mathrm{~Hz}, J=7.0 \mathrm{~Hz}, J=1.0 \mathrm{~Hz}, H_{5}$ )

Synthesis of $\left[\left(4-R^{\prime}-1 \text {-phenyl-1 } H \text {-benzotriazole }\right)_{2}\right],\left[R^{\prime}=(i B u)_{2} \mathrm{Al}(\mu-\right.$ TMP)Li], 3. In a Schlenk tube, 1-phenyl-1H-benzotriazole (195 mg, 1 $\mathrm{mmol}$ ) and LiTMP (147 mg, $1 \mathrm{mmol}$ ) were suspended in $n$-hexane (15 $\mathrm{mL})$ to give a pale yellow suspension. A solution of $\mathrm{iBu}_{2} \mathrm{Al}(\mathrm{TMP})(281 \mathrm{mg}$, $1 \mathrm{mmol})$ in $n$-hexane $(3 \mathrm{~mL})$ was added immediately to give a beige suspension, which was stirred for $2 \mathrm{~h}$ at room temperature. The 
suspension was filtered and the solid was washed with $n$-hexane $(3 \times 4$ $\mathrm{mL}$ ). Crystals of $\mathbf{3}$ suitable for an X-ray diffraction study were obtained by heating a suspension in $n$-hexane/methylcyclohexane to get a solution, and crystals grew when the Schlenk tube was placed in a refridgerator operating at $4{ }^{\circ} \mathrm{C}(319 \mathrm{mg}, 0.30 \mathrm{mmol}, 30 \%)$.

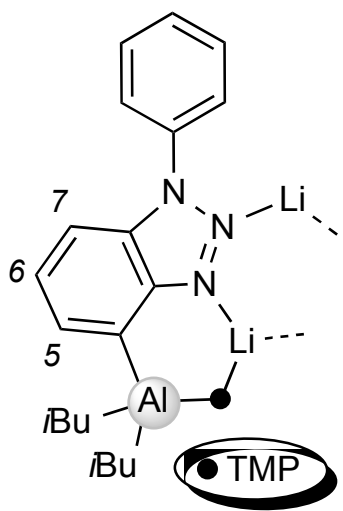

${ }^{1} \mathrm{H}$ NMR (400.13 MHz, $\left.\mathrm{C}_{6} \mathrm{D}_{6}, 300 \mathrm{~K}\right): \delta$ $8.30\left(\mathrm{~d}, 1 \mathrm{H}, J=6.4 \mathrm{~Hz}, H_{5}\right), 7.31(\mathrm{t}, 1 \mathrm{H}$ $\left.J=7.4 \mathrm{~Hz}, H_{6}\right), 6.92(\mathrm{~m}, 1 \mathrm{H},-P h), 6.88$ $\left(\mathrm{d}, 1 \mathrm{H}, \mathrm{J}=8.4 \mathrm{~Hz}, H_{7}\right), 6.85(\mathrm{~m}, 4 \mathrm{H},-P h)$ 2.25 (v br s, 2H, CH-iBu), 1.57 (s, 7H, $\mathrm{CH}_{3}$-TMP $+\mathrm{yCH}_{2}$-TMP), $1.46-1.29$ (overlapped br s + br d, $12 \mathrm{H}, \mathrm{CH}_{3}-\mathrm{iBu}$ ), 1.12-0.98 (br m, 8H, $\mathrm{CH}_{3}-\mathrm{TMP}+\mathrm{BCH}_{2}$ TMP), 0.87-0.70 (overlapped br $\mathrm{s}, 5 \mathrm{H}$ $\left.\mathrm{YCH} \mathrm{H}_{2}-\mathrm{TMP}+\mathrm{CH}_{2}-\mathrm{iBu}\right), 0.29 \mathrm{ppm}(\mathrm{v}$ br s $\left.2 \mathrm{H}, \mathrm{BCH}_{2}-\mathrm{TMP}\right) .{ }^{7} \mathrm{Li} \mathrm{NMR}(155.5 \mathrm{MHz}$, $\left.\mathrm{C}_{6} \mathrm{D}_{6}, 300 \mathrm{~K}\right): \delta 2.50 \mathrm{ppm} .{ }^{13} \mathrm{C}\left\{{ }^{1} \mathrm{H}\right\}$ NMR $\left(100.6 \mathrm{MHz}, \mathrm{C}_{6} \mathrm{D}_{6}, 300 \mathrm{~K}\right): \delta 153.8\left(C_{q}\right.$, benzotriazole), $135.9\left(C_{q}-\mathrm{Ph}\right), 135.8\left(C_{5}\right)$ $131.6 \quad\left(C_{q}\right.$-benzotriazole $), 130.9 \quad\left(C_{6}\right)$ 130.2 (C-Ph), $124.6(C-P h), 106.0\left(C_{7}\right)$, 53.2 ( $\mathrm{C}_{q}$-TMP), 43.5 (TMP), 37.7 (iBu), $30.3\left(\mathrm{CH}_{3}-\mathrm{iBu}\right), 30.0$ (br s, TMP), 29.2 ( $v$ br s, $\mathrm{CH}_{2}-\mathrm{iBu}$ ), 28.1 (TMP), 27.3 (iBu), 18.6 ppm (TMP). We only observe by 2D NMR spectroscopy the Al- $\mathrm{C}_{\mathrm{q}} \cdot{ }^{1} \mathrm{H},{ }^{13} \mathrm{C}-\mathrm{HMBC}$ NMR: $\delta$ $162.1 \mathrm{ppm}\left(\mathrm{Al}-\mathrm{C}_{\mathrm{q}}\right)$. We can observe by NMR spectroscopy a small amount of methylcyclohexane from the crystallization. ${ }^{1} \mathrm{H}-\mathrm{NMR}(400.13$ $\left.\mathrm{MHz}, \mathrm{C}_{6} \mathrm{D}_{6}, 300 \mathrm{~K}\right)$ of $\mathrm{C}_{7} \mathrm{H}_{14}: \delta 1.70-1.60(\mathrm{~m}, 5 \mathrm{H}), 1.30-1.15(\mathrm{~m}, 4 \mathrm{H}), 0.86$ ppm (d, 5H). ${ }^{13} \mathrm{C}-\mathrm{NMR}\left(400.13 \mathrm{MHz}, \mathrm{C}_{6} \mathrm{D}_{6}, 300 \mathrm{~K}\right)$ of $\mathrm{C}_{7} \mathrm{H}_{14}: \delta 35.6,32.9$, 26.7, 26.6, $23.0 \mathrm{ppm}$.

Elemental analysis calcd. (\%) for $\mathrm{C}_{65} \mathrm{H}_{102} \mathrm{Al}_{2} \mathrm{Li}_{2} \mathrm{~N}_{8}$ : C, 73.41; $\mathrm{H}, 9.67 ; \mathrm{N}$ 10.54; found: C, 73.15; $\mathrm{H}, 9.72$; N, 11.21 .

Synthesis of [(4-R'-1-phenyl-1H-benzotriazole)\{1-(2-R'-phenyl)-1H benzotriazole $]$, $\left[\mathrm{R}^{\prime}=(\mathrm{iBu})_{2} \mathrm{Al}(\boldsymbol{\mu}-\mathrm{TMP}) \mathrm{Li}\right], 4$. In a Schlenk tube, 1phenyl-1H-benzotriazole (195 mg, $1 \mathrm{mmol}$ ) and LiTMP (294 mg, $2 \mathrm{mmol}$ ) were suspended in $n$-hexane $(15 \mathrm{~mL})$ to give a pale yellow suspension. A solution of $i \mathrm{Bu}_{2} \mathrm{Al}(\mathrm{TMP})(562 \mathrm{mg}, 2 \mathrm{mmol})$ in $n$-hexane $(3 \mathrm{~mL})$ was added to give a beige suspension, which was stirred for $2 \mathrm{~h}$ at room temperature. The suspension was filtered and the solid was washed with $n$-hexane $(3 \times 4 \mathrm{~mL})$. Crystals of 4 suitable for an X-ray diffraction study were obtained by heating a suspension in $n$-hexane/methylcyclohexane to get a solution, and crystals grew when the Schlenk tube was placed in a freezer operating at $-15^{\circ} \mathrm{C}(357 \mathrm{mg}, 0.34 \mathrm{mmol}, 34 \%)$.

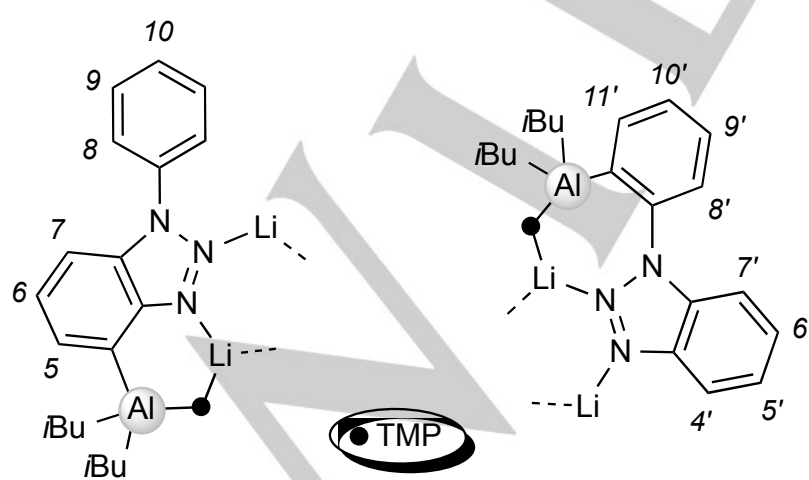

${ }^{1} \mathrm{H}$ NMR (400.13 MHz, C6 6 6, $\left.300 \mathrm{~K}\right): \delta 8.31$ (br d, $1 \mathrm{H}, J=6.8 \mathrm{~Hz}, \mathrm{H}_{8}$ ), $8.27\left(\mathrm{~d}, 1 \mathrm{H}, J=6.4 \mathrm{~Hz}, H_{7}\right), 8.16\left(\mathrm{v}\right.$ br d, $\left.1 \mathrm{H}, J=6.0 \mathrm{~Hz}, H_{7}{ }^{\prime}\right), 7.36(\mathrm{br}$ d, $\left.1 \mathrm{H}, J=7.8 \mathrm{~Hz}, H_{4}{ }^{\prime}\right), 7.27\left(\mathrm{~m}, 2 \mathrm{H}, H_{6}, H_{9}{ }^{\prime}\right), 7.10-6.95\left(\mathrm{~m}+\mathrm{t}, 4 \mathrm{H}, H_{10}, H_{10}{ }^{\prime}\right.$, $\left.H_{6}{ }^{\prime}, H_{5}{ }^{\prime}\right), 6.82\left(\mathrm{~m}, 3 \mathrm{H}, H_{5}, H_{9}\right), 6.68\left(\mathrm{~d}, 1 \mathrm{H}, J=7.8 \mathrm{~Hz}, H_{11}{ }^{\prime}\right), 6.46$ (br s
2H, $\mathrm{H}_{8}$ ), 2.40 (br s, 1H, CH-iBu), 2.14 (m, 2H, CH-iBu, $\mathrm{yCH}_{2}-\mathrm{TMP}$ ), 2.08$1.55(\mathrm{~m}, 19 \mathrm{H}, \mathrm{BBu}, \mathrm{TMP}), 1.46\left(\mathrm{~s}, 6 \mathrm{H}, \mathrm{CH}_{3}-\mathrm{iBu}\right.$ or $\left.\mathrm{CH}_{3}-\mathrm{TMP}\right), 1.44-1.10$ $(\mathrm{m}, 27 \mathrm{H}, i \mathrm{Bu}, \mathrm{TMP}), 0.85-0.70\left(\mathrm{~m}, 9 \mathrm{H}, \mathrm{CH}_{3}-\mathrm{iBu}, \mathrm{CH}_{3}-\mathrm{TMP}\right), 0.63(\mathrm{~m}, 3 \mathrm{H}$, $\left.\mathrm{CH}_{3}-\mathrm{iBu}\right), 0.47\left(\mathrm{~m}, 3 \mathrm{H}, \mathrm{CH}-\mathrm{iBu}, \mathrm{BCH}_{2}-\mathrm{TMP}\right),-0.20$ (br d, $\left.1 \mathrm{H}, \mathrm{CH}_{2}-\mathrm{iBu}\right),-$ $1.10 \mathrm{ppm}\left(\mathrm{m}, 1 \mathrm{H}, \mathrm{CH}_{2}-\mathrm{BBu}\right) .{ }^{7} \mathrm{Li} N \mathrm{NMR}\left(155.5 \mathrm{MHz}, \mathrm{C}_{6} \mathrm{D}_{6}, 300 \mathrm{~K}\right): \delta$ 2.58,2.24 ppm. ${ }^{13} \mathrm{C}\left\{{ }^{1} \mathrm{H}\right\}$ NMR (100.6 MHz, $\left.\mathrm{C}_{6} \mathrm{D}_{6}, 300 \mathrm{~K}\right): \delta 161.6$ (br s, Al$\left.C_{q}\right), 156.7\left(\mathrm{br} \mathrm{s}, \mathrm{Al}-C_{q}\right), 153.6\left(C_{q}\right), 146.1\left(C_{q}\right), 145.8\left(C_{8}{ }^{\prime}\right), 142.9\left(C_{q}\right)$, $135.5\left(C_{q}\right), 135.2\left(C_{7}\right), 133.7\left(C_{q}\right), 131.1\left(C_{q}\right), 130.6\left(C_{6}\right.$ or $\left.C_{9}{ }^{\prime}\right), 130.4$ (C9) 129.7, $129.1\left(C_{10}\right), 128.8,127.3,126.9\left(C_{10}\right), 124.2\left(C_{8}\right), 122.7\left(C_{11^{\prime}}\right)$, $118.6\left(C_{7^{\prime}}\right), 113.5\left(C_{4^{\prime}}\right), 105.6\left(C_{5}\right), 53.4\left(C_{q^{-T M P}}\right), 53.3\left(C_{q^{-T M P}}\right), 43.8$ (TMP), 43.4 (TMP), 38.8 (iBu), 37.9 (br s, iBu), 36.9 (br s, iBu), 31.5 $\left(\mathrm{CH}_{3}\right.$-iBu or $\left.\mathrm{CH}_{3}-\mathrm{TMP}\right), 31.1\left(\mathrm{CH}_{3}\right.$ - $\mathrm{iBu}$ or $\mathrm{CH}_{3}$-TMP $), 30.5\left(\mathrm{CH}_{3}\right.$ - $\mathrm{iBu}$ or $\mathrm{CH}_{3}$-TMP), 30.1, 29.7 (iBu or TMP), 29.2 (br s, $\left.\mathrm{CH}_{2}-\mathrm{iBu}\right), 28.3\left(\mathrm{CH}_{3}-\right.$ TMP), 27.9, 27.4 (br s, CH-iBu), 18.6 (TMP), 18.4 ppm (TMP). ${ }^{27} \mathrm{Al}$ NMR (104.2 MHz, $\left.\mathrm{C}_{6} \mathrm{D}_{6}, 300 \mathrm{~K}\right)$ : $\delta 148.80 \mathrm{ppm}$.

We can observe by NMR spectroscopy a small amount of methylcyclohexane/ $n$-hexane from the crystallization. ${ }^{1} \mathrm{H}-\mathrm{NMR}(400.13$ $\left.\mathrm{MHz}, \mathrm{C}_{6} \mathrm{D}_{6}, 300 \mathrm{~K}\right)$ of $\mathrm{C}_{7} \mathrm{H}_{14}: \delta 1.70-1.60(\mathrm{~m}, 5 \mathrm{H}), 1.30-1.15(\mathrm{~m}, 4 \mathrm{H}), 0.86$ ppm (d, 5H). ${ }^{13} \mathrm{C}-\mathrm{NMR}\left(100.6 \mathrm{MHz}, \mathrm{C}_{6} \mathrm{D}_{6}, 300 \mathrm{~K}\right)$ of $\mathrm{C}_{7} \mathrm{H}_{14}: \delta 35.6,32.9$, 26.7, 26.6, 23.0 ppm. ${ }^{1} \mathrm{H}-\mathrm{NMR}\left(400.13 \mathrm{MHz}, \mathrm{C}_{6} \mathrm{D}_{6}, 300 \mathrm{~K}\right)$ of $\mathrm{C}_{6} \mathrm{H}_{14}: \delta$ $1.24,0.89$ ppm. ${ }^{13} \mathrm{C}-\mathrm{NMR}\left(100.6 \mathrm{MHz}, \mathrm{C}_{6} \mathrm{D}_{6}, 300 \mathrm{~K}\right)$ of $\mathrm{C}_{6} \mathrm{H}_{14}: \delta 31.9$, 23.0, $14.2 \mathrm{ppm}$.

Elemental analysis calcd. (\%) for $\mathrm{C}_{64} \mathrm{H}_{102} \mathrm{Al}_{2} \mathrm{Li}_{2} \mathrm{~N}_{8}: \mathrm{C}, 73.11 ; \mathrm{H}, 9.78 ; \mathrm{N}$, 10.66; found: C, 73.01; H, 9.66; N, 10.89

Synthesis of dizincated 1-phenyl-1H-benzotriazole, 5. In a Schlenk tube, TMP $(\mathrm{H})(0.50 \mathrm{~mL}, 3 \mathrm{mmol})$ was added in THF $(7 \mathrm{~mL})$, and then reacted with $n B$ BuLi $(1.87 \mathrm{~mL}, 1.6 \mathrm{M}$ commercial solution in $n$-hexane, 3 $\mathrm{mmol}$ ) for $15 \mathrm{~min}$ at $0^{\circ} \mathrm{C}$, giving LiTMP in situ. $\mathrm{ZnCl}_{2} \cdot$ TMEDA (252 mg, 1 $\mathrm{mmol}$ ) was added and the mixture was stirred for $15 \mathrm{~min}$ at $0^{\circ} \mathrm{C}$, giving a yellow solution. At the same temperature, 1-phenyl-1H-benzotriazole (195 $\mathrm{mg}, 1 \mathrm{mmol}$ ) was introduced in the reaction, immediately the solution changed colour to orange. The reaction was stirring for $2 \mathrm{~h}$ at room temperature. After standing for one month at room temperature, the solution had darkened and deposited a small crop of crystalline material.

\section{Acknowledgements}

We are grateful to the UK Engineering and Physical Science Research Council (award no. EP/K001183/1 to R.E.M.), the Royal Society (Wolfson research merit award to R.E.M.), the Royal Society of Edinburgh (BP Trust Fellowship to S.D.R.) and NSERC Canada (Discovery Grant to V.S.) for financial support. Colleagues Eva Hevia, Charlie O'Hara and Donna Ramsay are also thanked for their astute inputs to the development of the project, together with Antonio J. Martínez-Martínez for help in constructing Figure 6.

Keywords: aluminium • lithium • metalation • structure elucidation $\bullet$ triazoles $\cdot$ zinc

References

[1] M. Schlosser, in Organometallics in Synthesis (Ed.: M. Schlosser), John Wiley \& Sons, Ltd., Chichester, 1994, p. 8.

[2] A. J. Martínez-Martínez, A. R. Kennedy, R. E. Mulvey, C. T. O'Hara Science 2014, 346, 834-837. 
[3] a) G. Wittig, U. Pockels, H. Dröge, Ber. Dtsch. Chem. Ges. 1938, 71, 1903-1912; b) H. Gilman, R. L. Bebb, J. Am. Chem. Soc. 1939, 61 109-112; c) P. Beak, R. A. Brown, J. Org. Chem. 1977, 42, 1823-1824 d) P. Beak, V. Snieckus, Acc. Chem. Res. 1982, 15, 306-312; e) M. P. Sibi, V. Snieckus, J. Org. Chem. 1983, 48, 1935-1937; f) V. Snieckus Chem. Rev. 1990, 90, 879-933; g) J. Mortier, J. Moyroud, B. Bennetau, P. A. Cain, J. Org. Chem. 1994, 59, 4042-4044; h) C. Metallinos, S. Nerdinger, V. Snieckus, Org. Lett. 1999, 1, 1183-1186; i) E. J. G. Anctil, V. Snieckus, J. Organomet. Chem. 2002, 653, 150-160; j) J. Clayden, in Organolithiums: Selectivity for Synthesis, Pergamon, Oxford, 2002 k) C. G. Hartung, V. Snieckus, in Modern Arene Chemistry (Ed.: D. Astruc), Wiley-VCH, New York, 2002, pp. 330-367; I) J. Clayden, in The Chemistry of Organolithium Compounds (Eds.: Z. Rappoport, I. Marek) Wiley, New York, 2004; m) M. C. Whisler, S. MacNeil, V. Snieckus, P. Beak, Angew. Chem. Int. Ed. 2004, 43, 2206-2225; n) T. K. Macklin, V. Snieckus, Org. Lett. 2005, 7, 2519-2522; o) M. Kauch, D. Hoppe, Synthesis 2006, 1578-1589; p) M. Kauch, D. Hoppe, Synthesis 2006 1575-1577; q) C. A. James, A. L. Coelho, M. Gevaert, P. Forgione, V. Snieckus, J. Org. Chem. 2009, 74, 4094-4103.

[4] A. J. Martinez-Martinez, D. R. Armstrong, B. Conway, B. J. Fleming, J. Klett, A. R. Kennedy, R. E. Mulvey, S. D. Robertson, C. T. O'Hara, Chem. Sci. 2014, 5, 771-781.

[5] E. Nagaradja, F. Chevallier, T. Roisnel, V. Dorcet, Y. S. Halauko, O. A. Ivashkevich, V. E. Matulis, F. Mongin, Org. Biomol. Chem. 2014, 12, 1475-1487.

[6] R. J. Less, V. Naseri, M. McPartlin, D. S. Wright, Chem. Commun. 2011, 47, 6129-6131.

[7] a) A. R. Katritzky, X. Lan, W.-Q. Fan, Synthesis 1994, 445-456; b) A. R. Katritzky, S. A. Henderson, B. Yang, J. Heterocyclic Chem. 1998, 35, 1123-1159; c) A. R. Katritzky, X. Lan, J. Z. Yang, O. V. Denisko, Chem. Rev. 1998, 98, 409-548; d) A. R. Katrizky, S. A. Belyakov, Aldrichimica Acta 1998, 31, 35-45; e) A. R. Katritzky, J. Heterocyclic Chem. 1999 36, 1501-1522; f) A. R. Katritzky, B. V. Rogovoy, Chem. Eur. J. 2003, 9 4586-4593; g) A. R. Katritzky, S. Bobrov, H. Tao, K. Kirichenko, Tetrahedron 2005, 61, 3305-3309.

[8] D. R. Armstrong, E. Crosbie, E. Hevia, R. E. Mulvey, D. L. Ramsay, S. D. Robertson, Chem. Sci. 2014, 5, 3031-3045.

[9] A. R. Kennedy, R. E. Mulvey, D. L. Ramsay, S. D. Robertson, Dalton Trans. 2015, 44, 5875-5887.

[10] J. Lee, S. H. Kim, K. M. Lee, K. Y. Hwang, H. Kim, J. O. Huh, D. J. Kim, Y. S. Lee, Y. Do, Y. Kim, Organometallics 2010, 29, 347-353.

[11] S. A. Sulway, D. Collison, J. J. W. McDouall, F. Tuna, R. A. Layfield, Inorg. Chem. 2011, 50, 2521-2526.

[12] a) D. R. Armstrong, D. Barr, W. Clegg, R. E. Mulvey, D. Reed, R. Snaith, K. Wade, J. Chem. Soc., Chem. Commun. 1986, 869-870; b) D. Barr, W. Clegg, R. E. Mulvey, R. Snaith, K. Wade, J. Chem. Soc., Chem. Commun. 1986, 295-297; c) D. R. Armstrong, D. Barr, W. Clegg S. M. Hodgson, R. E. Mulvey, D. Reed, R. Snaith, D. S. Wright, J. Am. Chem. Soc. 1989, 111, 4719-4727; d) R. Snaith, D. Barr, D. S. Wright, W. Clegg, S. M. Hodgson, G. R. Lamming, A. J. Scott, R. E. Mulvey, Angew. Chem. Int. Ed. Engl. 1989, 28, 1241-1243; e) R. E. Mulvey, Chem. Soc. Rev. 1991, 20, 167-209; f) W. Clegg, K. W. Henderson, L. Horsburgh, F. M. Mackenzie, R. E. Mulvey, Chem. Eur. J. 1998, 4, 53-
56; g) R. E. Mulvey, Chem. Soc. Rev. 1998, 27, 339-346; h) A. R. Kennedy, R. E. Mulvey, A. Robertson, Chem. Commun. 1998, 89-90; i) A. Downard, T. Chivers, Eur. J. Inorg. Chem. 2001, 2001, 2193-2201; j) W. Clegg, S. H. Dale, D. V. Graham, R. W. Harrington, E. Hevia, L. M. Hogg, A. R. Kennedy, R. E. Mulvey, Chem. Commun. 2007, 1641-1643.

[13] C. Lambert, F. Hampel, P. v. R. Schleyer, J. Organomet. Chem. 1993 455, 29-35.

[14] P. C. Andrews, W. Clegg, R. E. Mulvey, P. A. O'Neil, H. M. M. Wilson, J. Chem. Soc., Chem. Commun. 1993, 1142-1144.

[15] D. Rutherford, D. A. Atwood, J. Am. Chem. Soc. 1996, 118, 11535 11540.

[16] J. Garcia-Alvarez, E. Hevia, A. R. Kennedy, J. Klett, R. E. Mulvey, Chem. Commun. 2007, 2402-2404.

[17] a) A. Seggio, F. Chevallier, M. Vaultier, F. Mongin, J. Org. Chem. 2007 72, 6602-6605; b) A. Seggio, M.-I. Lannou, F. Chevallier, D. Nobuto, M Uchiyama, S. Golhen, T. Roisnel, F. Mongin, Chem. Eur. J. 2007, 13, 9982-9989; c) J.-M. L'Helgoual'ch, A. Seggio, F. Chevallier, M. Yonehara, E. Jeanneau, M. Uchiyama, F. Mongin, J. Org. Chem. 2008, 73, 177-183; d) K. Snégaroff, S. Komagawa, F. Chevallier, P. C. Gros, S. Golhen, T. Roisnel, M. Uchiyama, F. Mongin, Chem. Eur. J. 2010, 16, 8191-8201; e) F. Chevallier, Y. S. Halauko, C. Pecceu, I. F. Nassar, T. U. Dam, T. Roisnel, V. E. Matulis, O. A. Ivashkevich, F. Mongin, Org Biomol. Chem. 2011, 9, 4671-4684.

[18] a) P. García-Álvarez, R. E. Mulvey, J. A. Parkinson, Angew. Chem. Int Ed. 2011, 50, 9668-9671; b) D. R. Armstrong, A. R. Kennedy, R. E Mulvey, J. A. Parkinson, S. D. Robertson, Chem. Sci. 2012, 3, 2700 2707

[19] F. Blasberg, M. Bolte, M. Wagner, H.-W. Lerner, Organometallics 2012, 31, 1001-1005.

[20] A. L. Spek, Acta Crystallographica D 2009, 65, 148-155.

[21] a) A. R. Kennedy, J. Klett, R. E. Mulvey, D. S. Wright, Science 2009 326, 706-708; b) E. Crosbie, P. García-Álvarez, A. R. Kennedy, J. Klett, R. E. Mulvey, S. D. Robertson, Angew. Chem. Int. Ed. 2010, 49, 9388 9391.

[22] P. C. Andrikopoulos, D. R. Armstrong, H. R. L. Barley, W. Clegg, S. H. Dale, E. Hevia, G. W. Honeyman, A. R. Kennedy, R. E. Mulvey, J. Am Chem. Soc. 2005, 127, 6184-6185.

[23] L. Balloch, J. A. Garden, A. R. Kennedy, R. E. Mulvey, T. Rantanen, S. D. Robertson, V. Snieckus, Angew. Chem. Int. Ed. 2012, 51, 6934 6937

[24] J. C. Antilla, J. M. Baskin, T. E. Barder, S. L. Buchwald, J. Org. Chem. 2004, 69, 5578-5587.

[25] a) M. F. Lappert, M. J. Slade, A. Singh, J. L. Atwood, R. D. Rogers, R. Shakir, J. Am. Chem. Soc. 1983, 105, 302-304; b) E. Hevia, A. R. Kennedy, R. E. Mulvey, D. L. Ramsay, S. D. Robertson, Chem. Eur. J. 2013, 19, 14069-14075.

[26] R. E. Mulvey, D. R. Armstrong, B. Conway, E. Crosbie, A. R. Kennedy, S. D. Robertson, Inorg. Chem. 2011, 50, 12241-12251.

[27] G. M. Sheldrick, Acta Cryst. A 2008, A64, 112-122.

[28] V. Zimmermann, S. Bräse, J. Comb. Chem. 2007, 9, 1114-1137. 


\section{Entry for the Table of Contents}

\section{FULL PAPER}

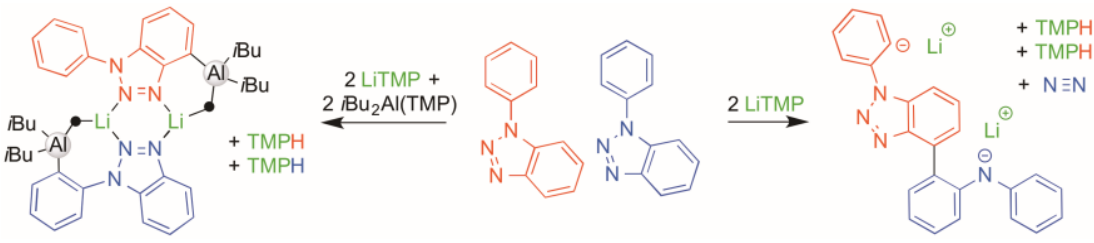

Sedate lithiation: Conventional lithiation of 1-phenyl-1H-benzotriazole destroys the heterocycle by ring opening, $\mathrm{N}_{2}$ extrusion and $\mathrm{C}-\mathrm{C}$ bond formation, but adding the trapping agent $i \mathrm{Bu}_{2} \mathrm{AlTMP}$ transforms the initial unstable $\mathrm{C}-\mathrm{Li}$ to stable $\mathrm{C}$-Al bonds sedating the sensitive carbanion to keep the triazole scaffold intact. This transmetal-trapping was established through isolation and structural characterization of bimetallic "intermediates"
M.A. Fuentes, A.R. Kennedy, R.E. Mulvey, * J.A. Parkinson, T. Rantanen, S.D. Robertson and V. Snieckus

Page No. - Page No.

Adding a Structural Context to the Deprotometalation and Trans-MetalTrapping Chemistry of Phenylsubstituted Benzotriazole 